DISABLED CHILDREN WRITE THEIR OWN BOOK: ENSURING DISABLED

CHILDREN'S RIGHTS, WELL-BEING, AND INTERESTS IN THEIR SERVICES

by

\author{
Jaclyn Ederman \\ Bachelor of Social Work \\ McGill University, 2012
}

A Major Research Paper

presented to Ryerson University

in partial fulfillment of the

requirements for the degree of

Master of Arts

in the Program of

Early Childhood Studies

Toronto, Ontario, Canada, 2014

(C) Jaclyn Ederman 2014 


\section{Author's Declaration}

I hereby declare that I am the sole author of this MRP. This is a true copy of the MRP, including any required final revisions.

I authorize Ryerson University to lend this MRP to other institutions or individuals for the purpose of scholarly research.

I further authorize Ryerson University to reproduce this MRP by photocopying or by other means, in total or in part, at the request of other institutions or individuals for the purpose of scholarly research.

I understand that my MRP may be made electronically available to the public. 


\title{
Disabled Children Write their Own Book: Ensuring \\ Disabled Children's Rights, Well-being, and Interests in their Services
}

\author{
(C) Jaclyn Ederman 2014 \\ Master of Arts \\ Early Childhood Studies \\ Ryerson University
}

\begin{abstract}
While the importance of disabled children's rights, well-being, and interests are frequently discussed internationally, how they are incorporated in services is rarely mentioned. This study explores traditional and non-traditional approaches by interviewing two community-based service-providers to illuminate which approach comes closer to ensuring disabled children's rights, well-being, and interests. Thematic analysis produced findings that acknowledged the extent to which the services differ including: service provided, program plans, benefits, and approach to challenges with children. The traditional approach positions disabled children as silent actors by taking control and by its formal structure. The non-traditional approach acknowledges disabled children as social actors by incorporating ways for children to exercise control of their own lives and by its informality, which promotes disabled children's individuality. These factors suggest the non-traditional approach comes closer to ensuring disabled children's rights, well-being, and interests. Implications are significant for reconsidering practice and policies in the hope that disabled children's rights in services are ensured for future generations.
\end{abstract}

Key words: disability, children's rights, well-being and interests, applied behaviour analysis, non-traditional approaches, alternative approaches 


\section{Acknowledgements}

I am thankful to the many individuals in my life who have made this Major Research Paper possible and who have supported me in this journey:

My family, Mom, Dad, Shawn, Carey, Griffin, Ashley, Carter - Thank you for putting up with me through my never ending countless complaints, for taking care of me, and always believing in me.

My supervisor, Dr. Melanie Panitch - I could not have completed this research study without you. Your guidance, advice, support, ongoing encouragement, and immense knowledge has taught me so much and for that I am thankful.

To Dr. Rachel Berman and Dr. Mehrunnisa Ali - Both of you have been welcoming, supportive, and have pushed me this year and for that I am thankful as it has contributed to me pursuing this research study. I am thankful for your assistance and to have had both of you on my committee.

To the rest of the Ryerson faculty who I have learned from this year and to Natalya Androsova, who helped developed my writing skills these past few months, I am thankful for all of your support and advice.

I would like to thank my participants, for without them, this research study would not have been able to happen.

Last, but for sure not least, my friends and family members - Cohort: I am so thankful to have met all of you this year. We have made the most amazing memories, in class, in the lounge, and hanging out - both good and bad - and I hope they continue, mostly the good. My other friends and family members: Thank you for still liking me after I have ignored most of you for the past few months because of this research study. I love you all always. 


\section{Table of Contents}

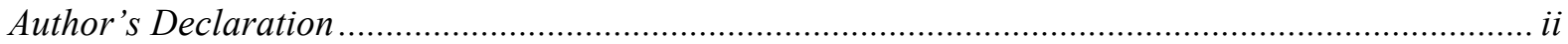

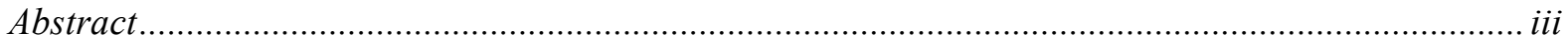

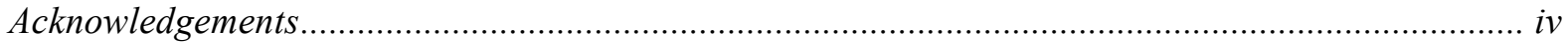

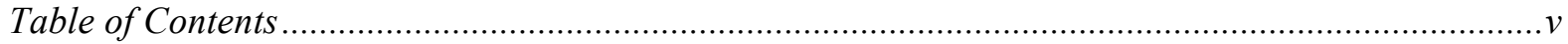

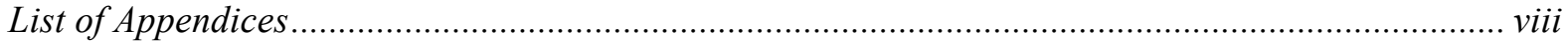

Chapter 1 - Introduction ............................................................................................................................ 1

Problem

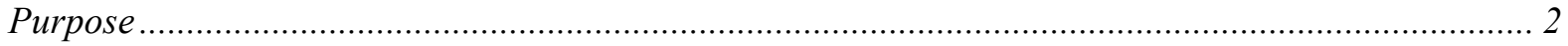

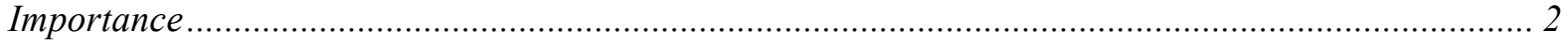

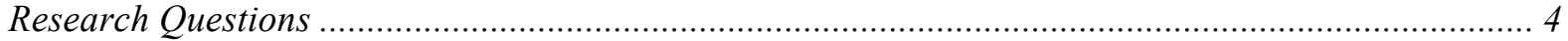

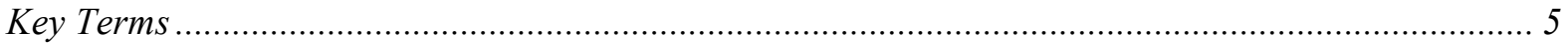

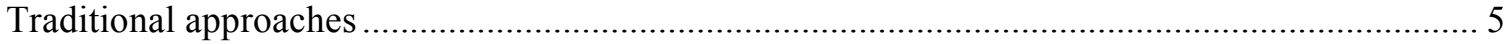

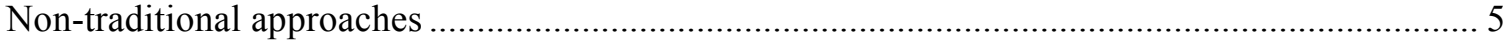

Chapter 2 - Conceptual and Theoretical Frameworks......................................................................... 7

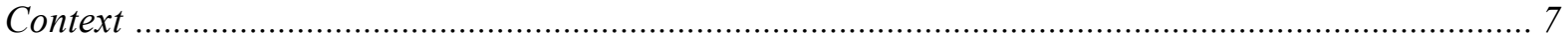

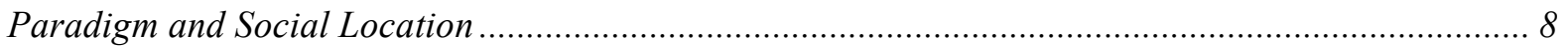

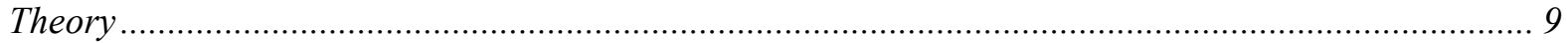

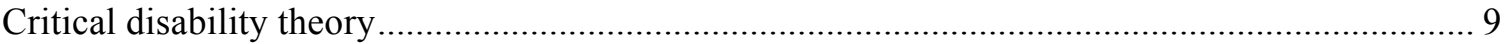

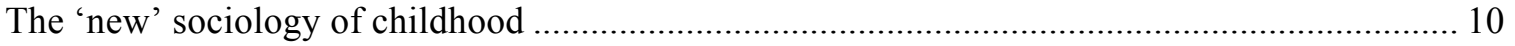

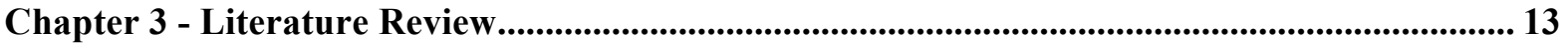

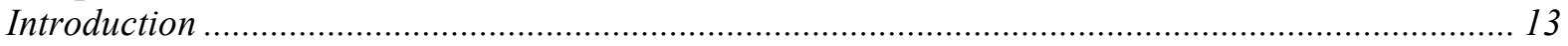

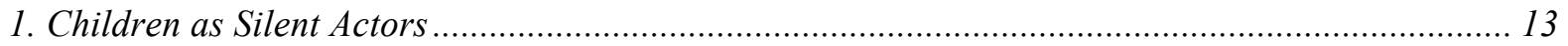

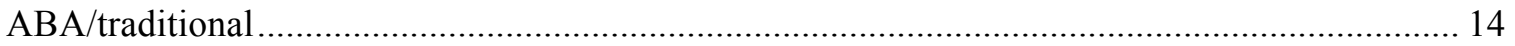

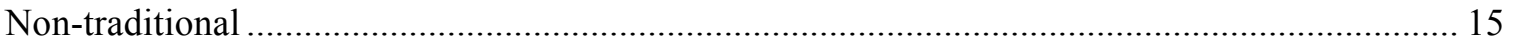

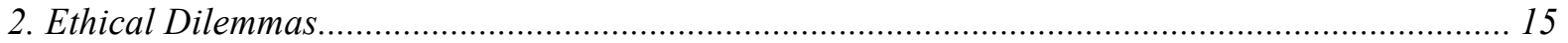

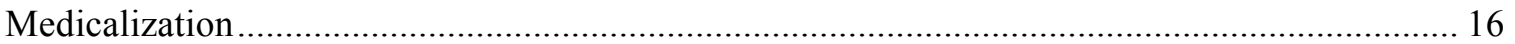

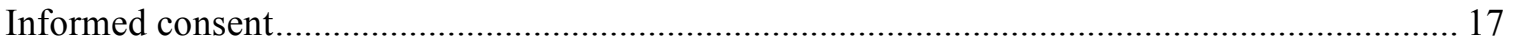

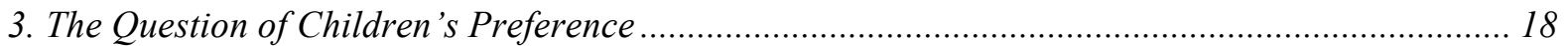

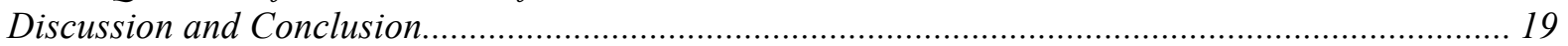

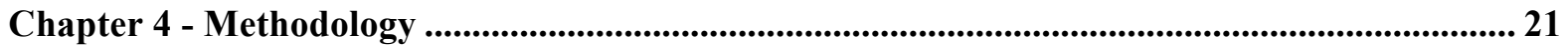

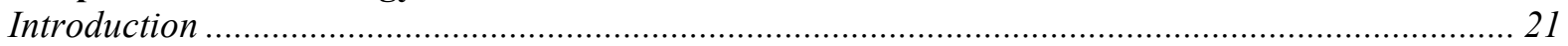

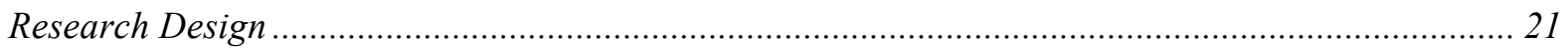

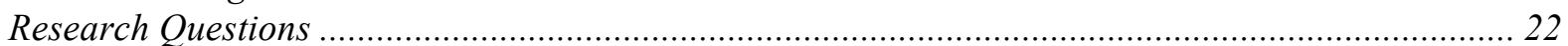

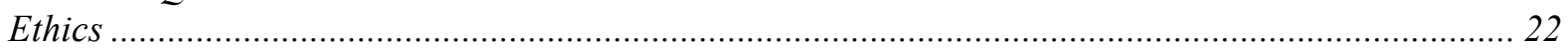

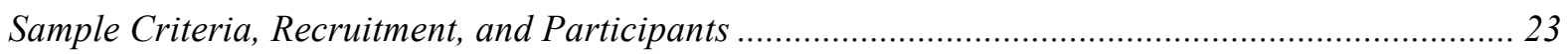

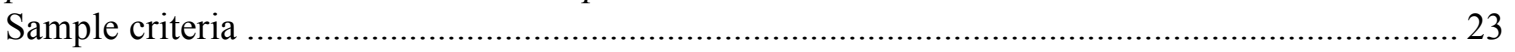

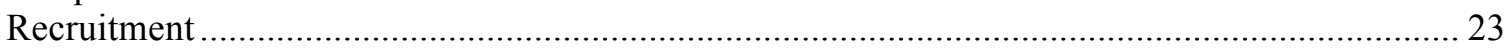

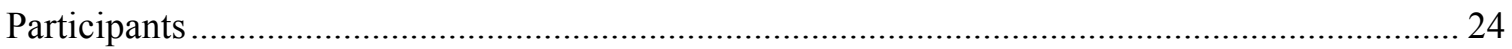

Instruments and Measures of Data Collection and Analysis......................................................... 24

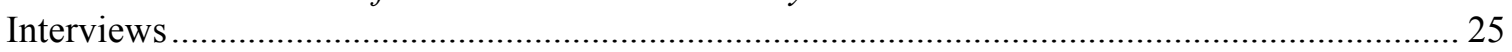

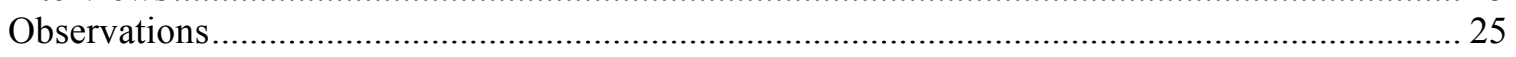

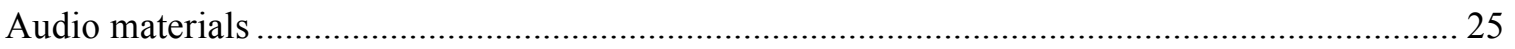

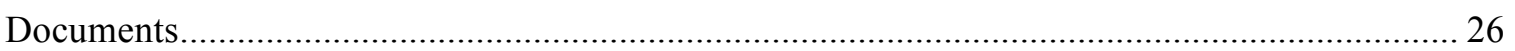

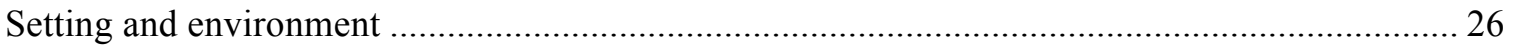

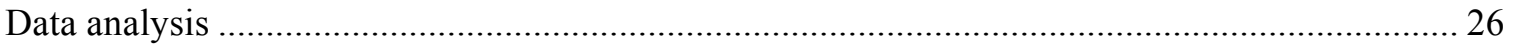

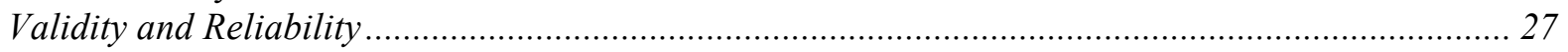

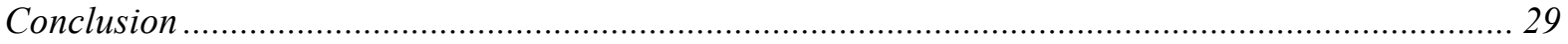




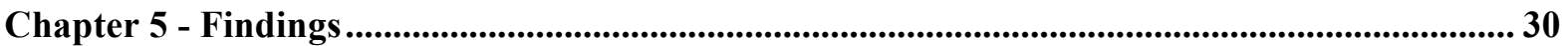

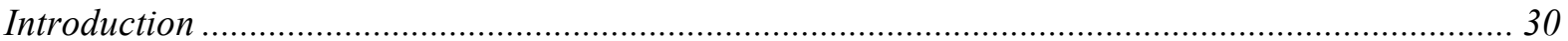

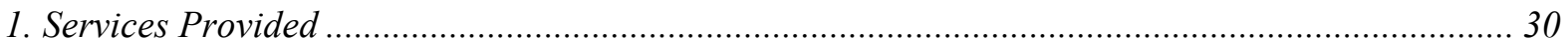

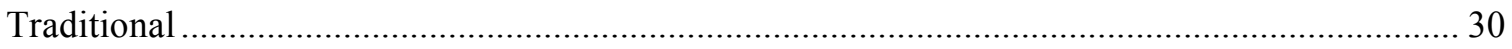

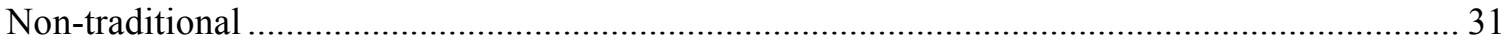

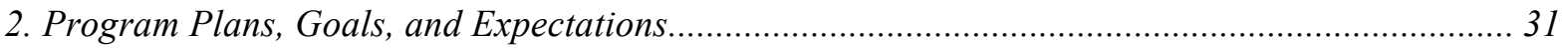

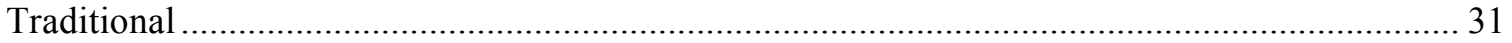

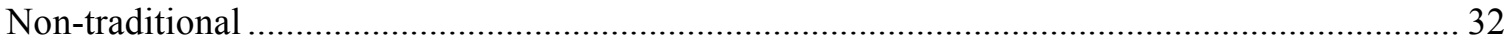

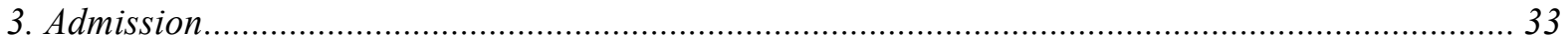

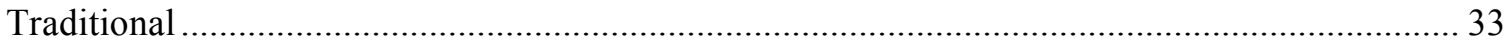

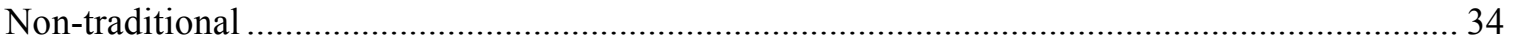

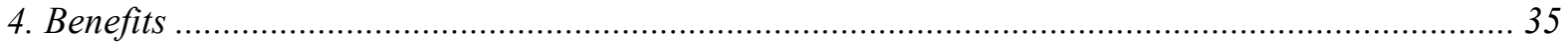

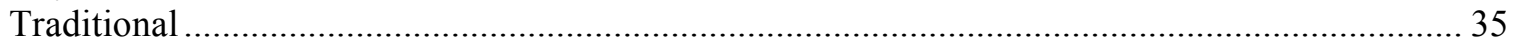

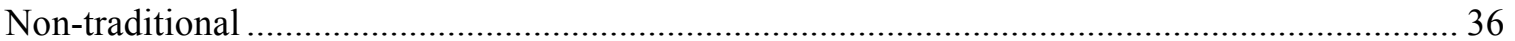

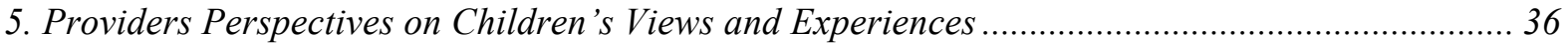

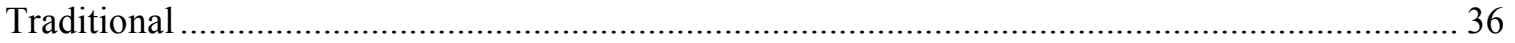

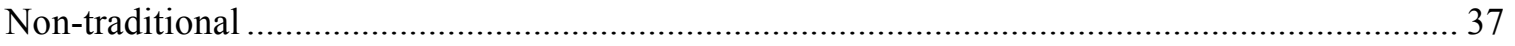

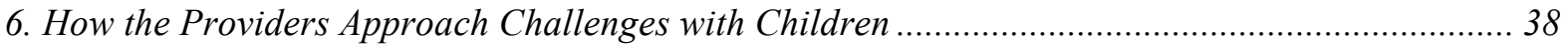

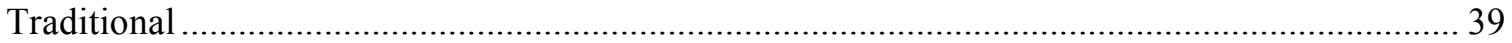

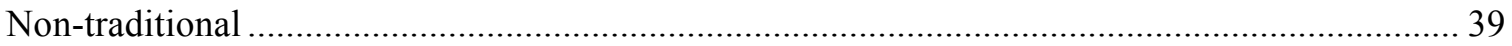

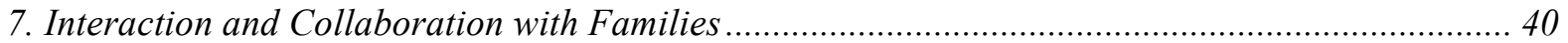

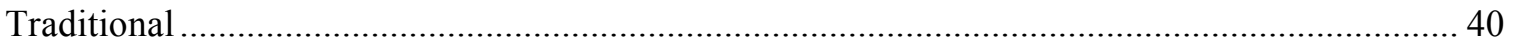

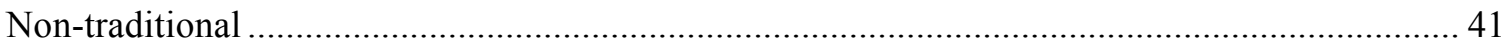

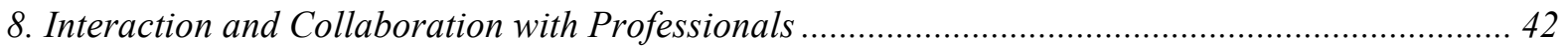

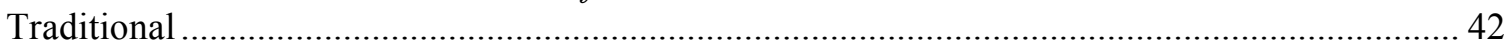

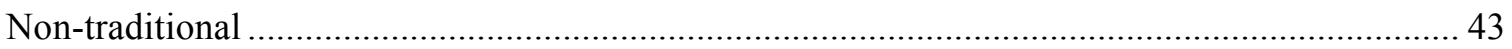

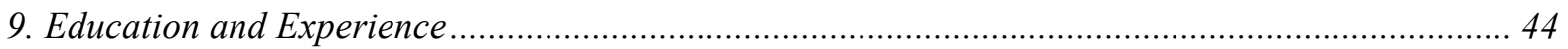

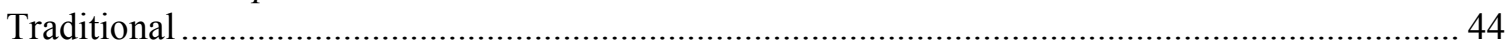

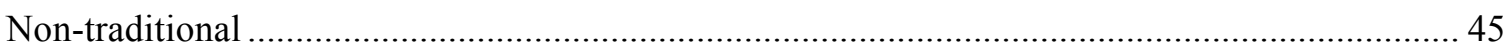

10. Challenges and Limitations they Experience with the Program and Field ................................ 45

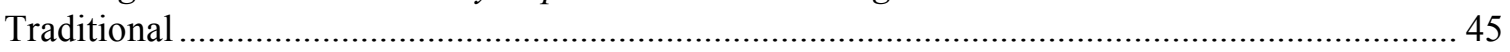

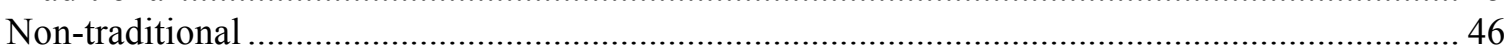

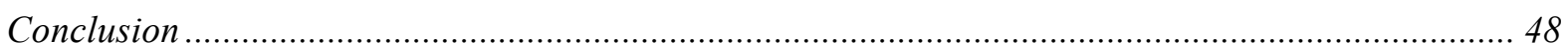

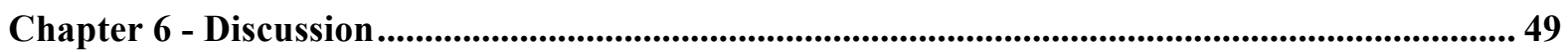

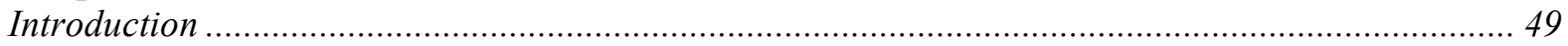

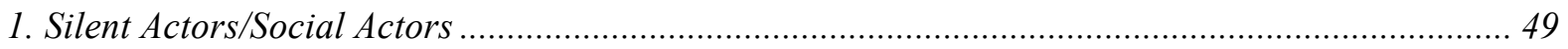

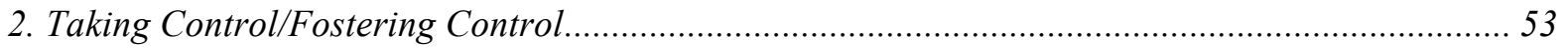

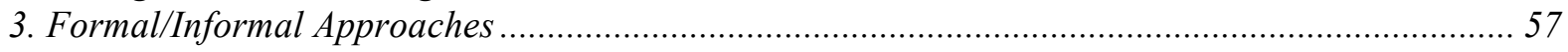

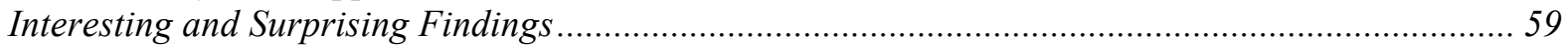

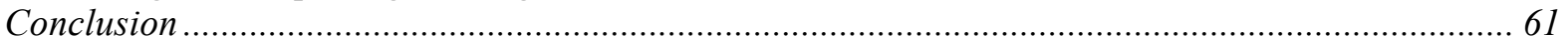

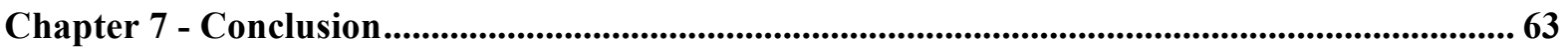

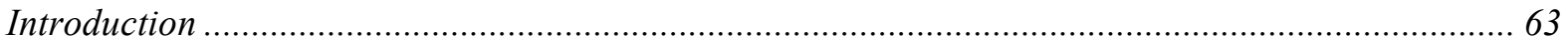

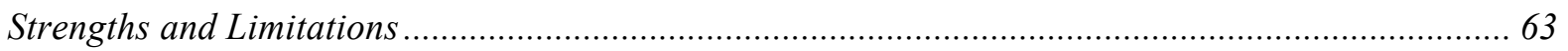

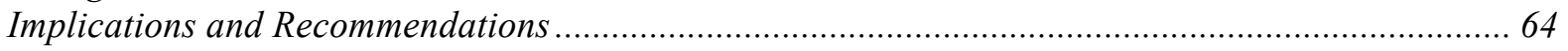

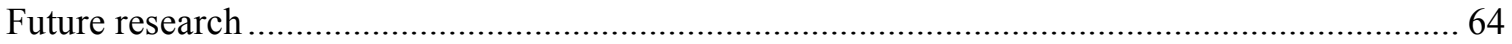

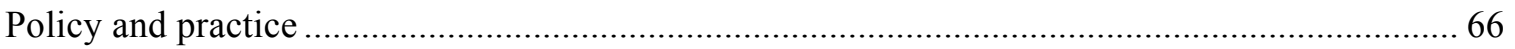

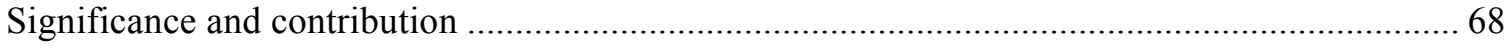

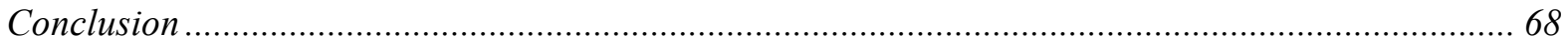




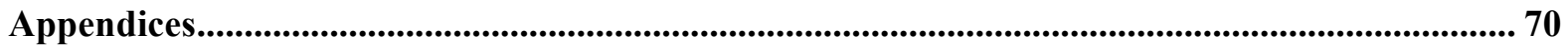

Appendix A - Ryerson Research Ethics Board Approval ............................................................. 70

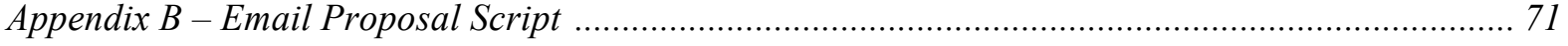

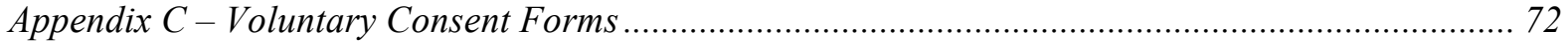

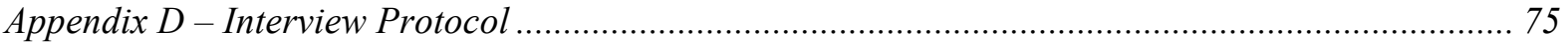

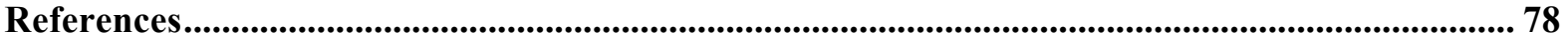




\section{List of Appendices}

Appendix A. Ryerson Research Ethics Board Approval....................................70

Appendix B. Email Proposal Scripts.............................................. 71

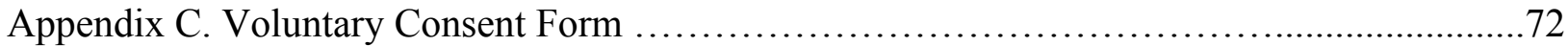

Appendix D. Interview Protocol.................................................. 75 


\section{Chapter 1 - Introduction}

\section{Problem}

The dominant ideology and approach to disability in western society is based on the medical model. Within the medical model, assumptions of individuals are made based on characteristics and abilities (Iannacci \& Graham, 2013; Kapp, 2011; Smart, 2009). The medical model defines and categorizes individuals according to their deficit and as a result, positions individuals with a disability on a lower status for which they are stigmatized as disabled individuals and are perceived as needing support and assistance. The dominance of the medical model helps explain why there has been an increase in the number of children labeled as having disabilities (Iannacci \& Graham, 2013; Kapp, 2011; Smart, 2009).

A more holistic perspective and approach to understanding disability is the social model, which takes a more socio-political approach to disability (Kapp, 2011; Smart, 2009). The social model focuses on issues of prejudice and oppression, and it argues that the way society is organized inherently denies the inclusion of certain individuals (Watson, 2012). The social model recognizes disability as diversity, and therefore promotes individual rights and well-being for all members of society (Kapp, 2011; Smart, 2009).

As the medical model is the dominant ideology, most professionals work within it and tend to refer disabled children and families to services based on traditional approaches of therapy that perpetuate the same societal constructs and values with which they have been trained (Gasalberti, 2006; Iannacci \& Graham, 2013; Nieuwenhuys, 2013). Traditional approaches primarily focus on fixing the child through techniques such as behaviour modification, which is inherent in the common traditional approach of Applied Behaviour Analysis (ABA). ABA is a “one size fits all” approach for children with Autism Spectrum Disorders (ASD) (Glynne-Owen, 
2010, p. 405). However, a "one size fits all" approach raises a number of questions, such as: how can there be a "one size fits all" approach for children with ASD when ASD presents itself so differently in each child? Who deems ABA effective? Are there alternative non-traditional approaches one can consider (Gasalberti, 2006; Glynne-Owen, 2010; Ladd, 2005)?

Non-traditional approaches to service provision may be a useful subject of inquiry to address these questions, as employing a single therapy for all children with Autism Spectrum Disorders may be limiting (Gasalberti, 2006). Non-traditional approaches may incorporate aspects of disabled children's rights, well-being, and interests, and these are key components in the social model (Gasalberti, 2006; Kapp, 2011; Smart, 2009). These components may not be taken into consideration when discussing the limits of traditional approaches such as Applied Behaviour Analysis and are the elements I wish to address in this study.

\section{Purpose}

The purpose of this study is to explore both traditional and non-traditional approaches by examining two community-based services and service-providers for disabled children in order to illuminate which service approach comes closer to ensuring disabled children's rights, wellbeing, and interests. This will be done through understanding disabled children as social actors, by recognizing disabled children's voices, opinions, and rights, and by examining the various ways that children learn through the diverse methods of practice (Graham \& Fitzgerald, 2011; Iannacci \& Graham, 2013; Lenz-Taguchi, 2011; Matthews, 2007; Tisdall, 2012).

\section{Importance}

This study is important given that disabled children's rights, well-being, interests, and inclusion in general, have been on the international agenda since the development of the U.N. Convention on the Rights of the Child (CRC) in 1990 and the development of the U.N. 
Convention on the Rights of Persons with Disabilities (CRPD) in 2008 (Glynne-Owen, 2010; Unicef, 2014; United Nations, 2014; United Nations, 2009; United Nations, 1990). Both the CRC and CRPD are guided by values that support children's rights and interests and promote equality, respect, non-discrimination, and participation. The conventions attempt to ensure that children should be able to speak freely about aspects that affect their own lives while they encourage values such as listening to children's voices and opinions (United Nations, 2014; United Nations, 1990). These ongoing international discussions surrounding disabled children children's rights and well-being to ensure equality within society is the context in which this research emerges.

This study is also important as it emphasizes children's voices with particular reference to the services they receive. There are many services for disabled children in Ontario (such as schools, hospitals, and rehabilitation programs) however research and evaluations of these services tend not to include disabled children's views (Heitzman-Powell, Buzhardt, Rusinko, \& Miller, 2014; Juneja, Mukherjee, Sharma, Jain, Das, \& Sabu, 2012; Ministry of Children and Youth Services [MCYS], 2013). As a result, this may be seen as perpetuating the infringement of disabled children's rights as their voices are silenced.

Ajodhia-Andrews and Berman (2009) researched disabled children's perspectives about their school life and Stalker and Connors (2003) researched disabled children's perceptions of their own disability. Both of these research teams found creative ways of maintaining children's participation and communication throughout their research studies. The findings from AjodhiaAndrews and Berman (2009) and Stalker and Connors (2003) illuminate that disabled children are not only able to express themselves, but also their perceptions and opinions came through very powerfully. As a result, these findings may assist parents, professionals, service providers, 
and policy makers to find ways to take disabled children's values and attitudes into consideration throughout their services.

Finally, this research is important, because it may build upon and contribute to new work in the field that in the future may explore disabled children's perceptions about issues that affect their daily lives. It seems reasonable to assume that with the establishment of the CRC and CPRD, both of which Canada has signed, disabled children's rights, well-being, and interests are considered or at least talked about throughout service provision. In this study I have investigated how and if disabled children's rights, well-being, and interests are being taken into consideration throughout the types of services they receive, while keeping in mind the two international conventions that articulate the importance of disabled children having the right to form opinions and express their views in areas that relate to their lives.

\section{Research Questions}

Through a case study of two community-based organizations that assist disabled children, this study explores the overall programs and activities that are involved in traditional and nontraditional approaches. The primary research question guiding this study is: which approach comes closer to ensuring disabled children's rights, well-being, and interests? Towards understanding the overriding research question of the study, I also drew upon questions such as: Are disabled children's voices incorporated into their programming? Are disabled children's rights incorporated? Are they promoted? Are they ensured? In which ways do service providers or in which ways do they not ensure disabled children's rights, well-being, and interests?

Disabled children's rights, well-being, and interests are operationalized based on whether children have a say in their programs, if their preferences are taken into consideration, and how the providers respond to challenges they experience with children. Another indicator is whose 
goals (providers, parents, children's) are uppermost in mind throughout the delivery of services as well as what those goals are.

\section{Key Terms}

Traditional approaches. The most common traditional approach to supporting children with Autism Spectrum Disorders (ASD) is Applied Behaviour Analysis (ABA). The extensive research and evidence supporting ABA has demonstrated its effectiveness for improving children's cognitive levels, communication abilities, and developing other skills, which has led to its popularity throughout Ontario and North America (Hayward, Gale, \& Eikeseth, 2009; McPhilemy \& Dillenburger, 2013; MCYS, 2011a; Steege, Mace, Perry, \& Longenecker, 2007). $\mathrm{ABA}$ is based on the science of behaviour analysis and learning theory and uses a systematic process to improve socially appropriate behaviours while concurrently hindering inappropriate behaviours manifested in the child (MCYS, 2011a; Steege et al., 2007). ABA uses strict and consistent selected guidelines and principles, is provided on an individual basis with an ABA specialist, and is intensive as children complete between 20 to 40 hours of ABA each week (Hayward et al., 2009; MCYS, 2011a). ABA involves ongoing evaluations and assessments of the child where target behaviours are marked accordingly. As children complete the stages of ABA, assessments are conducted and marked off, and when the child has reached the necessary goal they are able to move on to the next stage (Heitzman-Powell, 2014; Juneja et al., 2012; MCYS, 2011a).

Non-traditional approaches. Non-traditional approaches encompass an array of services, resources, and programs that support disabled children and the approaches incorporate a number of fields within helping professions (April, Feldman, Zunzunegui, Descarreaux, \& Grilli, 2009; Gasalberti, 2006). These include, but are not limited to relaxation imagery, music therapy, 
and animal-assisted therapy. Given the variety of non-traditional approaches, depending on the child and the program, outcomes and benefits vary and are set accordingly. For example, animalassisted therapy introduces animals, primarily dogs and horses, into therapeutic settings as an adjunct. Some of the recognized benefits of animal-assisted therapy for disabled children are developing bonds, increasing language and socialization skills, decreasing anxiety, and motivating children through activities instead of tasks (April et al., 2009; Gasalberti, 2006; Prothmann, Ettrich, \& Prothmann, 2009; Sams, Fortney, \& Willenbring, 2006; Silva, Correia, Lima, Magahaes, \& deSousa, 2011). 


\section{Chapter 2 - Conceptual and Theoretical Frameworks}

\section{Context}

The context that frames this research derives from ongoing interest and discussion about disabled children's rights and well-being that is currently being deliberated in the public arena, within social policies, in educational settings, and within the academy amongst researchers. Disabled children's rights have been on the international, national, and provincial political agenda since the establishment of the U.N Convention on the Rights of the Child (CRC) and the U.N Convention on the Rights of Persons with Disabilities (CPRD) (Unicef, 2014). Discussion and media coverage on Autism Spectrum Disorders (ASD) and disabilities frequently appear in newspapers such as the Globe and Mail, the Toronto Star, and the Ottawa Citizen. Monthly, disability-related articles may be found that report on such topics as acceptance for disabled children, advocacy for equality, and alternative views on disabilities (Currie, 2014; Goar, 2014; Robb, 2014).

Disability can include physical and developmental disabilities, behavioural and emotional challenges, and a variety of other chronic mental health conditions and disorders such as blind/low vision, ASD, deafness, speech impairments, and down syndrome (Leeb, Bitsko, Merrick, \& Armour, 2012; MCYS, 2013). Given the complexity and diversity that disability presents, it is challenging to identify how many individuals experience disability. However recent statistics suggest that in Ontario, disability is experienced by around $15 \%$ of individuals at

all ages (Heitzman-Powell et al., 2014; Juneja et al., 2012; MCYS, 2013; Ministry of Community and Social Services [MCSS], 2008). These varying numbers are also apparent for children in Ontario as it is estimated that 97,000 to 235,000 children and youth experience disability (MCYS, 2013). Setting this study in Ontario is significant given that Ontario was 
ranked as having the largest number of children with acute and/or severe special needs of any Canadian province or U.S state, and in 2010/2011 approximately 319,200 children in Ontario school boards were reported as receiving special education programs and or services (Bennett \& Wynne, 2006; Ministry of Education, 2014).

In Ontario there has been an increase in the numbers of children being labeled with a disability and who have Autism Spectrum Disorders; currently, rates are around 1 in 150 (MCYS, 2011a; MCYS, 2011b). Being labeled as ASD is based on The Diagnostic and Statistical Manual of Mental Disorders (DSM-5); children fall into the category of ASD if they have disorders including autistic disorder, asperger's, childhood disintegrative disorder, and pervasive developmental disorder-not otherwise specified (American Psychiatric Association, 2013; Young \& Rodi, 2014). The DSM-5 describes children who have ASD as having challenges with their social and communication skills, as they tend to differ from what society views as typical by displaying repetitive behaviours and experiencing challenges developing bonds with other individuals (American Psychiatric Association, 2013; Young \& Rodi, 2014). The increase in children being labeled disabled and in particular the increase in number of children being labeled as having Autism Spectrum Disorders has resulted in increased funding for Applied Behaviour Analysis services by the Ontario government (MCYS, 2011a; MCYS, 2011b).

\section{Paradigm and Social Location}

Given that my research is action oriented, that it stems from societal issues of inequality, social justice and rights, and that it focuses on power and change, I situate myself in the transformative paradigm (Creswell, 2014). My related experiences, encounters, and values personal, educational, volunteer, professional - have led me to my research on disabled children's rights and well-being. My lived experiences of disability have not only pushed me to 
learn to advocate for myself but has also encouraged me to pursue education and research in the field in hopes of changing the lives of others and society at large.

My Bachelor of Social Work Degree has provided me with an understanding of the complex situations and experiences that children and families face. I have worked and learned in a variety of settings such as a school for deaf children, an integrative preschool, a group home

for adults with dual diagnosis, and with children in the foster care system. My current Master of Arts, Early Childhood Studies Degree has opened my eyes into reconceptualizing dominant ideologies that abound our society. I have been able to gain insight and learn about the underlying issues that surround marginalized and oppressed groups that are ultimately rightsbased issues and this, as a result, has lead me to pursue this research study.

\section{Theory}

The theoretical perspectives of critical disability theory and the 'new' sociology of childhood guide this qualitative research study as they provide me with a lens into studying complex issues within the marginalized group of disabled children (Creswell, 2014).

Critical disability theory. Critical disability theory discusses the complexity of disability as a discourse in relation to knowledge and power within society and within this, critical disability theory addresses both the medical model and the social model (Iannacci \& Graham, 2013; Watson, 2012). For example, given that the medical model labels children thereby constructing and limiting how children are perceived within society, critical disability theory considers the medical model to be the main reason in why there is a rise in the number of children diagnosed as having disabilities. Concurrently, critical disability theory also analyzes and questions the societal challenges that the social model evokes (Iannacci \& Graham, 2013). 
Critical disability theory also explores how the discourse of disability is connected to dominant societal values and norms, which impact the functioning of our society and systems within it such as services and policies (Iannacci \& Graham, 2013). This perspective theorizes that within our society "identities are socially constructed" and deconstructs the impact that constructed language has on individuals (Iannacci \& Graham, 2013, p. 57). Language has perpetuated binaries surrounding disability within our society such as being abled/disabled and given the power imbalances and inequalities in society, able-bodied individuals are positioned with more power than disabled individuals. These factors are evident in schools where it is mandatory for children to take the Education Quality and Accountability Office (EQAO) Tests and if children do not meet the standards they are perceived to have deficits as they are compared to others (Iannacci \& Graham, 2013). Labeling perpetuates the view that disabled children and individuals need assistance and as a result disability is viewed negatively and such negative connotations surround disability discourse (Kapp, 2011).

The critical disability theory framework allows me to critique deficit-based discourses and power imbalances throughout the service approaches in my study by using an asset-oriented approach to acknowledge that disabled children are competent, knowledgeable, and equal (Iannacci \& Graham, 2013). Similarly, as the critical disability theory framework seeks to concurrently shift, destabilize, attempt to capture, and question the dominant discourse of disability, this perspective allows me to shed light on and consider how alternative service approaches providing programs for disabled children compare to traditional approaches such as Applied Behaviour Analysis (Iannacci \& Graham, 2013).

The 'new' sociology of childhood. The 'new' sociology of childhood, also critiques dominant ideological socialization and developmental theories which hold negative views and 
assumptions about children (Matthews, 2007; Tisdall, 2012). Through this reconceptualization, the 'new' sociology of childhood views children as social actors by recognizing children's abilities as being experts in their own lives and having competence to contribute to society as children rather than only in the future as adults. The 'new' sociology of childhood also challenges the homogenizing affect that dominant ideologies have caused and instead promotes the diversity of children within cultures and contexts. In addition, the 'new' sociology of childhood examines relationships and power hierarchies between adults and children which have left children to be marginalized, silenced, and seen from a deficit perspective given that they are always being compared to adults (Matthews, 2007; Tisdall, 2012). These components have led to the advocacy of rights, participation, and voice of children within the 'new' sociology of childhood framework as generally parents, teachers, and other adult figures have spoken for children (James, 2007).

The 'new' sociology of childhood framework enables me to critique dominant ideologies of the notion of the "child" and "childhood" through my exploration of possible power hierarchies in service provision between children and adults. This framework also enables me to see if children are perceived as social actors with competencies, if their rights and views are taken into consideration, or if they are silenced throughout the service approaches. This research study acknowledges and utilizes both critical disability theory and the 'new' sociology of childhood collaboratively to frame and address the complex topic of ensuring disabled children's rights and well-being in service provision. In particular, through using these theories, I am able to critique dominant ideologies while concurrently focusing on the oppression that the concepts of "disability" and "child" and "childhood" represent in society and in addition examine if 
children's participation, voices, and rights are taken into consideration throughout two opposing service approaches (Iannacci \& Graham, 2013; Tisdall, 2012). 


\section{Chapter 3 - Literature Review}

\section{Introduction}

Article 4 in the U.N Convention on the Rights of Persons with Disabilities (CRPD), established in 2009 and adopted by Canada in 2010, recommends that policies and programs promote and protect human rights for disabled individuals, yet Article 4 is ambiguous as it does not indicate how and what this specifically means (United Nations, 2014). This ambiguity raises interesting questions. For example, do disabled children have a choice in their services? Do disabled children really have rights if others are choosing programs for them? As this research study explores how and if disabled children's rights, well-being, and interests are ensured in two service approaches, this literature review explores existing literature on both traditional approaches and on non-traditional approaches to reveal what most aligns with disabled children's rights, well-being, and interests as upheld by international conventions.

This chapter provides a scoping review on the most up to date and relevant literature on both approaches. Through analyzing the literature, it was found that disabled children's rights, well-being, interests, voices, and opinions are infrequently mentioned in both approaches, and overall children appear as silent actors. To support this notion, the following sections will provide a review of the literature on Applied Behaviour Analysis (ABA) and on non-traditional approaches. Major themes that are present within the literature are discussed in the sections below under the following headings: (1) Children as Silent Actors, (2) Ethical Dilemmas, and (3) The Question of Children's Preference.

\section{Children as Silent Actors}

The literature on Applied Behaviour Analysis and on non-traditional approaches primarily focuses on the programs, parents' experiences of programs, and benefits of these 
programs. It appears that the literature fails to mention disabled children's accounts and perceptions about the programs and instead is bound by accounts from others who speak for them, including professionals, providers, researchers, and parents. This section explores how children appear as silent actors first, within the literature with regard to ABA/traditional approaches and second, within the literature regarding non-traditional approaches.

ABA/traditional. Professional and parental accounts abound in the literature on ABA approaches and experiences and as a result, professionals and parents are the ones who decide if ABA is effective. For example, in terms of ABA approaches, Hayward et al. (2009) argue for a new model of $\mathrm{ABA}$ and base their information solely on parental and providers' thoughts and decisions about programming results. Hayward et al. (2009) state motivational operations are used in the ABA approach to incorporate children's interests for developing language. However, they fail to mention if children enjoy these components as they are only spoken about from the perspective of the parent and or the professional. Steege et al. (2007) critique the variety of components that are present in one program compared to another, and specify the necessity of all components within the ABA approach. However no indication is made as to why the components are necessary and to whom it matters, so the question remains as to whether children's voices are incorporated in decisions of necessary components?

The literature focusing on ABA experiences, such as the work of McPhilemy and Dillenburger (2013) and the work of Grindle, Kovshoff, Hastings, and Remington (2009) explores experiences from families' perspectives however they neglect to incorporate disabled children's perceptions of ABA. Based on the studies presented above, it is difficult to deduce whether or not children are dissatisfied with ABA because their accounts and voices have been omitted from the literature. If the literature surrounding ABA's program and experiences are 
continually bound by accounts from others, how are we able to know if children are dissatisfied with their services as they are constantly excluded from the conversation?

Non-traditional. The literature on the variety of non-traditional approaches and programs is also bound by professionals, parents, and researchers' accounts. For example, April et al. (2009) researched the perceived effectiveness of non-traditional approaches but only interviewed parents. Gasalberti (2006) argued the benefits of non-traditional approaches for disabled children and state non-traditional approaches may be more useful given that they target each child individually however the literature does not mention if children chose these programs or if their parents did. Gasalberti (2006) states equine therapy enables disabled children to have fun throughout their therapeutic program although still does not mention children's rights in choice or options within the approach. Gasalberti (2006) further argues that animal-assisted therapy and the overall addition of owning a pet within a family with a disabled child is beneficial as "70\% reported an increase in domestic happiness" (p. 134). Even though these results are high, the findings discussed above might indicate a professional and adult hierarchy as disabled children's voices and rights were not mentioned, suggesting children as silent actors in their services and thus raising an ethical dilemma. Ethical dilemmas relating to children's' rights are discussed in the following section.

\section{Ethical Dilemmas}

The literature indicates disabled children as silent actors in both service approaches as others represent children's voices. As a result, ethical dilemmas related to medicalization and informed consent can occur. The available literature on ethical dilemmas primarily focuses on and critiques Applied Behaviour Analysis. 
Medicalization. A key ethical dilemma that is mentioned in the literature derives from the medicalization of Autism Spectrum Disorders (ASD) itself that has produced the Applied Behaviour Analysis approach. There appears to be some conflicting issues in terms of the definition of ASD. For example, the reasoning behind defining ASD in such broad terms is to not limit children's available services, but rather by producing one category for the spectrum, children then become eligible for all the services (American Psychiatric Association, 2013). Glynne-Owen (2010) argues this process to be contradictory as how can children, with such unique and different defining characteristics of ASD, all fit into a single approach such as of ABA when it is designed in such a rigid manner?

Glynne-Owen (2010) further argues the ABA approach is deficit-based and notes ABA is designed to normalize children, which is similar to the argument made by Ladd (2005) who references the Michelle Dawson/Auton case. For example, the Michelle Dawson/Auton case may be seen as a direct critique of normalization, as Dawson, diagnosed with ASD, disputes the ABA approach and argues individuals with ASD are able to contribute to society without first having to conform (Ladd, 2005). Individuals in society are set up for ABA services given that ABA is the predominant source of funding and service for individuals with ASD. This ethical question revolves around why individuals should have to alter their behaviours to conform to perceived societal norms if they do not want to and why isn't there a choice for funded alternative options?

Ladd (2005) also identifies barriers with Dawson's argument such as: (1) ASD individuals have trouble developing bonds and will not conform on their own, (2) ASD individuals are not happy as they present behaviours which appear to display frustration, and (3) society is structured to support typically developing children and adults and in order to provide the most success in their future we should normalize them so they will have access to that future. 
Although Ladd (2005) also presents strong points against the case, the points omit disabled children's rights, well-being, and interests. These statements are condescending, judgmental, and do not consider what children want or if they even enjoy the Applied Behaviour Analysis approach and program.

Informed consent. Another ethical dilemma is that of informed consent. Ladd (2005) asks an important question related to how families can give informed consent without truly knowing the outcomes of $\mathrm{ABA}$ and without including what the child wants in the decision. Similarly, Glynne-Owen (2010) critiques professionals, researchers, and others in the field given that many assume that they know what it means to have ASD, understand what it means to have an ASD, and as a result, have the ability to make decisions for disabled children with ASD. Given that no one should be able to make a decision for another, regardless of disability, and that disabled children, in accordance with the U.N CRC and the U.N CPRD, do have the right to make decisions, have opinions, and participate actively in aspects that relate to their lives, it may be seen that disabled children's rights are being infringed upon.

If disabled children's rights and voices were included, we might be able to inquire about what disabled children want within their lives and their service provision. As mentioned earlier, research is beginning to incorporate disabled children's voices in both the design and implementation of the studies. Here the work of Ajodhia-Andrews and Berman (2009) illuminate how a non-verbal disabled child is able to express himself about his perceptions and opinions on his schooling. This work illuminates how it is possible to understand and listen to disabled children's voices in order to uphold their rights and well-being. However it appears that the medicalization of ASD, inherent societal values that support ABA, and consent and lack of consent appears to limit disabled children's opportunities to do so. Having said this, the question 
of children's preferences in their services is explored in the next section.

\section{The Question of Children's Preference}

There is virtually no literature on children's preferences in the Applied Behaviour Analysis programs and approach in comparison to other approaches. However, in the literature on non-traditional approaches, children's preferences were examined for research purposes only. Although the literature on non-traditional approaches do not mention disabled children's rights, the notion that disabled children's preferences are being explored is a positive indication that rights and well-being might be taken into consideration in the future.

There has been a body of literature devoted to investigating if children with Autism Spectrum Disorders have more of an interest in working with humans, animals, and or toys for therapeutic purposes to support the research on children's interest in working with animals (Prothmann et al., 2009; Sams et al., 2006; Silva et al., 2011). Prothmann et al. (2009) explored children with ASD's preferences to working with a therapy dog, toys, or a therapist and results indicated children chose the dog more frequently and in those sessions appeared happier. Prothmann et al. (2009) also provided children with three choices, which enabled children to develop a sense of control and choice. However, there was no indication of what the children did in the sessions themselves and as a result it is unclear if children's voices were maintained throughout the sessions.

Sams et al. (2006) found children with ASD to have a preference for occupational therapy that combined animal-assisted therapy instead of the children's standard occupational therapy sessions. Results from this study suggested that incorporating animals enabled the children to be more motivated and engaged given that they enjoyed participating. Silva et al. (2011) researched a 12-year-old boy with ASD and compared his experiences with animal 
assisted therapy to with that of working under the control of a sole therapist. Findings suggested that interventions with animal-assisted therapy made the child happier and it was noted the child was smiling, was physically engaged, and exhibited a decrease in negative behaviours.

The research studies presented above suggest that children with Autism Spectrum Disorders prefer interventions that include animals although they do not mention if children had their choices maintained throughout the sessions or if these choices were made for the children. Consequently, this may indicate some infringement of children rights even though they appeared to have enjoyed the sessions. In addition, the literature supporting children's preferences were conducted as research studies only and do not represent actual services and programs. However the language in the literature on children's preferences, use terms such as "motivated, engaged, and sense of control" suggesting that non-traditional approaches lean towards language that reflects a valuing of children's rights, well-being, and interests. On the other hand, the minimal literature on children's preferences in Applied Behaviour Analysis may suggest traditional approaches have not yet come close to considering children's rights, well-being, and interests.

\section{Discussion and Conclusion}

The literature on Applied Behaviour Analysis and non-traditional approaches present disabled children as silent actors and as a result pose ethical dilemmas in terms of their rights, well-being, and interests. April et al. (2009) and Glynne-Owen (2010) both argue in order for disabled children to participate fully and have their rights met, disabled children should be involved in a collective and collaborative approach to their services and be incorporated as a part of the decision making processes. However, this type of involvement does not appear to be incorporated within either approach. 
While the medicalization of Autism Spectrum Disorders, as defined by the DSM-5, combines autistic disorder, asperger's, childhood disintegrative disorder, and pervasive developmental disorder into one category does have the advantage of ensuring children access to services and treatments by professionals, the approach and delivery of the service (i.e. Applied Behaviour Analysis) causes concerns (American Psychiatric Association, 2013; Young \& Rodi, 2014). For example, as ASD is a spectrum and presents itself differently in each child, the question is raised as to whether or not the one size fits all approach of ABA works for all children with ASD in light of their individual differences and the unique expressions of their disabilities (Gasalberti, 2006; Glynne-Owen, 2010)?

As this literature review also presented research on children's preference, it seems worth studying if children do have a preference or interest or are able to actively choose, have a voice, and have rights overall in the services they receive when it comes to both Applied Behaviour Analysis and non-traditional approaches. Ladd (2005) notes ABA components to be extremely rigid, repetitive, and exhausting to children. With this in mind, one wonders from a child's perspective whether this would be enjoyable? Who deems these approaches effective? If the approach is not "working," one might try another approach or gain the child's perspective in order to see what they would like or what they need.

This chapter provided a scope on the available literature on both traditional and nontraditional approaches and it appears there is limited research available on children's rights, wellbeing and interest in both approaches to service provision. As a result, this research study is important as it can begin to fill the gap in the literature addressing disabled children's rights, well-being, and interests in their services. The next chapter examines the methodology used in this research study. 


\section{Chapter 4 - Methodology}

\section{Introduction}

This chapter provides information about the research approach and methodology used in conducting this research study. I begin by discussing my overall research design and restating my research questions. I then move on to discuss my sample criteria, recruitment process, and my participants as well as note the instruments I used for data collection and analysis. This section concludes with my rationale for these measures as they enabled validity and reliability for my study.

\section{Research Design}

I chose a qualitative approach for this research study for many reasons. As there is limited literature available on disabled children's rights, well-being, and interests in their service provision, a qualitative approach enabled me examine and understand this topic based on my interviews, analysis, and discussion (Creswell, 2014). Qualitative approaches have been recognized to be useful for researchers, such as myself, who are in the field of disability studies (Maxwell, Hano, \& Skivington, 2007). Similarly, as qualitative approaches are also inductive, and as disabled children's rights, well-being, and interests are complex, this approach enabled me to conceptualize, deconstruct, and examine the multifaceted levels within both approaches (Creswell, 2014). More specifically, this approach enabled me to explore what service providers had to say in relation to their approaches and programs while concurrently shedding light and questioning if disabled children's rights, well-being, and interests were addressed in both service approaches (Creswell, 2014; Maxwell et al., 2007).

I used the strategy of a case study. Case studies are used for "evaluation, in which the researcher develops an in-depth analysis of a case, often a program, event, activity, process, or 
one or more individuals" (Creswell, 2014, p. 14). Similar to most qualitative case studies, my literature review was utilized to provide background on the limited information available on disabled children's rights, well-being, and interests in service approaches which is the reason and justification for this research study (Creswell, 2014). A case study enabled me to explore and understand the realities of disabled children's rights and well-being within the both service approaches while extracting my knowledge and experience on a topic of interest.

\section{Research Questions}

Through a case study of two community-based organizations that provide services to disabled children, this study explored the overall goals, programs, and activities that are involved in traditional and non-traditional approaches. This research study sought to investigate the following question: which approach comes closer to ensuring disabled children's rights, wellbeing, and interests? To understand the overriding research inquiry of the study, I looked at such questions as: Are disabled children's voices incorporated into their programming? Are disabled children's rights incorporated? Are they promoted? Are they ensured? How do the service providers or how do service providers not ensure disabled children's rights, well-being, and interests?

Disabled children's rights, well-being, and interests were operationalized based on whether children have a say in their programs, if their preferences are taken into consideration, and how the providers respond to challenges they experience with children. In addition, what and whose goals are primary throughout service provision were also considered.

\section{Ethics}

Prior to conducting the study I applied to Ryerson's Research Ethics Board as my research involved human participants. Research Ethics Board's are utilized before research 
begins in order to "provide protection against human rights violations" (Creswell, 2014, p. 95). An application went in to Ryerson's Research Ethics Board on April 29, 2014 and the study received approval on May 20, 2014. The approval letter may be found in Appendix A.

\section{Sample Criteria, Recruitment, and Participants}

Sample criteria. My purposive sample included two service providers who offer programs for disabled children and in particular I examined one traditional and one nontraditional approach service-provider. The criteria for selecting the service providers were: one individual who provided a traditional service (i.e. one Applied Behaviour Analysis specialist) and one individual who provided a non-traditional service (i.e. animal-assisted therapy, music therapy, etc.). Additional criteria for both providers were that they were currently practicing and providing services to disabled children because they would be able to provide me with current information about the services they provide and their approaches used in the programs and would be experienced and richly knowledgeable sources of information. In addition, the participants also had to speak English and be working within the Greater Toronto Area.

Recruitment. I purposefully selected my participants from a variety of professionals that I know. Purposefully selecting participants was chosen as it enabled me to choose serviceproviders who would be able to offer me the most information and assist me in understanding the different approaches and thus develop my research inquiry and analysis (Creswell, 2014). I emailed two service-providers to inform them of my study and provided them with a brief proposal to see if they were interested in participating. The proposal can be found in Appendix B. As recognized by Creswell (2014), the proposal included information about my research study's purpose, what the participants would be asked to do, and ensured the participants that Ryerson's Research Ethics Board had approved the study. I had two proposals that I emailed to 
the potential participants that were based on the services that they provide. One of the scripts was targeted to the traditional approach provider (ABA specialist) and the other script was targeted to the non-traditional approach provider. I intentionally made the scripts almost identical, as I did not want to assume any bias, acknowledging that both services are helpful supports for disabled children.

As required, I provided both participants with a voluntary consent form. The consent form can be found in Appendix C. The participants were able to look it over prior to the interview and sign before participating in the research. The consent form addressed any potential risks and benefits of participating in the study, ensured the participants that all their information would remain confidential, noted that participation was voluntary, and stated that they could choose to answer or not answer any questions throughout the interview (Creswell, 2014). In addition, the voluntary consent form also provided contact information if the participants wanted further information regarding the study or had questions about the study.

Participants. Two participants were selected for this research study, one ABA specialist, and one individual who offers a variety of private non-traditional programs for disabled children. In addition to the aforementioned criteria, I also purposefully selected the two participants as they are knowledge rich individuals and would be able assist me most in understanding the approaches I was investigating for this study (Creswell, 2014).

\section{Instruments and Measures of Data Collection and Analysis}

This research study used multiple instruments and measures of data collection in order to obtain the most information possible (Creswell, 2014). I collected the data utilizing four methods: (1) Interviews, (2) Observations, (3) Audio Materials, and (4) Documents. 
Interviews. The first method used was interviews. Interviews were used to allow the participants to recall and provide information about their current as well as past experiences and practices (Creswell, 2014). I conducted semi-structured interviews with each participant separately. One interview was conducted at the beginning of the week and another was conducted at the end of the same week. This was done in order to not have a full day of interviews and in accordance with the participants' schedules.

The interviews were guided by an interview protocol that I created which can be found in Appendix D. The interview protocol was led by questions about their service such as: Who do you serve? What program do you offer? How is your service funded? The interview protocol included primarily open-ended questions. Open-ended questions enabled me to maintain control over the interviews while concurrently allowing the participants to speak freely and allowed for flexibility given that some questions and answers were expanded by the use of prompts which led to other ideas entering the conversation (Creswell, 2014). I also encouraged participants to ask questions if they needed clarification or if they wanted to discuss something in order to build a rapport and make the interview more welcoming.

Observations. Observations were the second method of data collection used in this research study. I had a note pad with me to write observations during each interview. This method enabled me to be a key instrument in the data collection process as I observed and noted the participants' body language and unusual aspects of each interview that I would not have been able to remember (Creswell, 2014).

Audio materials. The third method of data collection was through utilizing audio materials. Upon permission, I audiotaped the interviews. This was done in order to focus my attention on each participant throughout each interview instead of being distracted by writing 
notes given that I did not write notes the whole time, only for unusual aspects as mentioned above (Creswell, 2014).

Documents. The last method of data collection was through documents. I referred to documents from each participant's web pages and program brochures. These documents assisted in my analysis because I was able to access additional information about the program at a later date (Creswell, 2014).

Setting and environment. My interviews were set in natural settings as "qualitative researchers tend to collect data in the field at the site where participants experience the issue or problem under study" (Creswell, 2014, p. 185). I conducted my research where the participants felt most comfortable and during a time that was convenient for them given that I did not want to impose on either participant (Creswell, 2014).

The interview with the ABA service provider took place at a school in a room during lunch hour when children were not around. The participant informed me that this was a convenient time and place for her. We closed the door to have little distraction and to ensure confidentiality. The interview with the non-traditional service provider took place in a room near a farm where she provides some of her programs. It took place at a convenient time for her, in the morning, prior to children arriving to programming in order to ensure little distraction and maintain confidentiality.

Data analysis. A qualitative case study approach enabled me to interpret the two serviceproviders' approaches and analyze how they align with disabled children's rights, well-being, and interests and in order to do so I went through a number of processes. Prior to analyzing the data, I first organized my data by participant and transferred each audio recording onto my locked computer to maintain confidentiality. As case studies require accurate portrayal of 
characteristics of the participants in the study to examine issues, I transcribed each interview and typed up all of my observation notes on Microsoft Word (Creswell, 2014). Once transcribed, I listened to the audio recordings again, went through all of the data, and read my typed notes multiple times in order to ensure accuracy, gain a larger understanding of the data, and conceptualize my thoughts about the information (Creswell, 2014).

I then developed a holistic account of the findings by depicting strong narratives of each participant's perceptions (Creswell, 2014). I began coding which is a "process of organizing the data by bracketing chunks (or text or image segments) and writing a word representing a category in the margins" (Creswell, 2014, p. 198). This process enabled me to begin to cluster and label topics and themes in broader categories and begin to identify descriptive words to represent the categories. I used colour highlighters throughout this process to narrow down and identify codes and themes. As qualitative research is inductive, I used inductive data analysis to slowly build themes and patterns from the four sources of data through segmenting the data and to interpret the participants' meanings (Creswell, 2014). Given that I obtained such rich and detailed data, I winnowed the data to focus on the data relevant to my study as well as findings which I found to be unexpected (Creswell, 2014).

\section{Validity and Reliability}

I used a number of strategies to support the validity, reliability, and overall credibility of this study. Increasing the validity in my study was necessary given validity builds merit for qualitative research (Creswell, 2014). Validity is "based on determining whether the findings are accurate from the standpoint of the researcher, the participant, or the readers of an account" (Creswell, 2014, p. 201). The strategies of clarifying my bias and prolonged time in the field have been utilized throughout the study to support validity and credibility. In chapter two, I 
discussed my paradigm, social location, and theoretical standpoint. This shed light on my long time personal and educational background and experiences that has enabled me to pursue my interest in the field and this study. In addition, the findings and discussion chapters provide comments to support how I came to my interpretations and conclusions (Creswell, 2014).

The strategy of triangulation was also used to provide rationale for my themes. I drew upon multiple data sources such as my observation, notes, brochures, and transcriptions from both participants in order to establish the commonalities and detect themes (Creswell, 2014). I used rich thick descriptions from my setting and my in my findings of the themes to add to the validity given that the illustrations supported perspectives on my themes (Creswell, 2014).

I also utilized the strategy of peer and supervisor debriefing to increase authenticity of my descriptions, explanations, and conclusions at numerous stages of the research study and development of this paper. In order to see if my interpretation resonated with other individuals, two graduate student peer debriefers in my program reviewed parts of the study as well as a graduate writing support specialist at Ryerson University (Creswell, 2014). In addition, supervisor debriefing was also completed throughout all stages of the study. My supervisor, an experienced researcher, educator, worker, and professor in the field of disability studies, analyzed and assisted me throughout the development of this research study.

I took a number of steps to support the reliability of this study because an increase in reliability demonstrates that my approach is consistent and stable (Creswell, 2014). A variety of procedures are suggested to increase reliability of a study. Documentation is noted to increase reliability and throughout the study I produced detailed documentation all of my processes about the case study (Creswell, 2014). For example, I made notes during each step of the study and have them saved on my computer in organized files. I also listened to the audio files multiple 
times and checked transcripts to ensure they were accurate. I also met with my supervisor weekly to communicate about my coding and analysis to make sure there was no confusion about definitions. In addition, I provided a clear and concise interview protocol that may be used by others who might like to conduct the same study or a similar study (Creswell, 2014).

\section{Conclusion}

This chapter provided a detailed description of the research design utilized for this study by providing examples and information about the ethical considerations, my sample criteria, recruitment, and participants involved. In addition, by providing background on my instruments and measures of data collection and analysis, and the clarification processes put in place to support the validity and reliability of this study, I hope to have provided a clear contextual picture about what steps were involved in this research study and my approach. The examples provided an understanding of the processes and interpretations of how this study was set out and what led to me conduct my research and analyze the data. The following chapter examines the findings from the data collected. 


\section{Chapter 5 - Findings}

\section{Introduction}

This chapter offers findings from data collected from interviews and web documents (which will not be disclosed to maintain confidentiality) on the traditional provider and the nontraditional provider. As this study is focused on disabled children's rights, well-being, and interests in their services, only data crucial to discussion and conclusion will be included. The pseudonym of Rachel is used to represent the Applied Behaviour Analysis (ABA) provider/traditional approach and the pseudonym of Liz is used to represent the non-traditional provider/approach.

The following sections depict narratives from both service-providers. The sections are organized according to the topics of: (1) Services Provided, (2) Program Plans, Goals, and Expectations, (3) Admission, (4) Benefits, (5) Providers Perspectives on Children's Views and Experiences, (6) How the Providers Approach Challenges with Children, (7) Interaction and Collaboration with Families, (8) Interaction and Collaboration with Professionals, (9) Education and Experience, and (10) Challenges and Limitations they Experience with the Program and the Field. Each section will begin with perspective and voice from traditional provider and will follow with the non-traditional provider in order to illuminate how and where the approaches differ and are similar.

\section{Services Provided}

This section explores what services are provided to disabled children and where are the services provided.

Traditional. Rachel is an Applied Behaviour Analysis specialist who works for an organization in Ontario for children who receiving direct funding for ABA services. Rachel's 
ABA takes place in both children's homes and at their school if the school permits access. Each week children are allotted and funded for 20 hours of ABA. Ten hours must be within the hours of a school day (i.e. Monday to Friday, 9 to 3), while the other 10 hours are during after school hours (i.e. weekdays after 3:30 or weekends). The times and hours differ each week depending on the availability of school, the ABA specialist, and the family.

Non-traditional. Liz is the owner and director of nine private programs for disabled children and youth. Her programs run throughout the year, and depending on the program, differ in time and location. She offers five programs in group format, two programs in individual format, and two programs in family format. The group programs include: a city summer camp (daily for 6 weeks in July and August), a farm riding camp (daily for 3 weeks in August), a city bike program (once a week, from May to June), a gym program (once a week, from September to April), and a youth recreation program (once a week, all year). Her individual programs include:

therapeutic riding (once a week, all year) and a dog program (once a week). Her family programs include: assisting families who have children with Autism Spectrum Disorders (ASD) and their dogs and supporting and planning for one family and their two children.

\section{Program Plans, Goals, and Expectations}

This section examines how the programs are planned, what the goals are, and the expectations.

Traditional. Children in the ABA program have their own individual plan. Rachel notes that the sessions "are all the same...everyday in a certain way, with a certain reinforcement schedule." Rachel uses the assessment tool called Assessment of Basic Language and Learning Skills (ABLLS), which include goals based on areas such as life skills, math, writing, group skills, social interaction, labeling, interverbal, syntax, and grammar. The ABBLS book provides 
breakdowns of each of the goals that children must accomplish to move onto the next level and Rachel follows it. For example when labeling 100 items, Rachel starts with the first box which requires a child to label 5 items and then she increases with different preferred and non-preferred items in order to finish the goal.

She expects children to meet the goals and the length varies depending on their developmental level. She notes how "ABA is very robotic" and states "you are going to learn about this pen...if it takes you 10 hours...every session you are going to learn about a pen, 5 minutes, 7 minutes, day in and day out"...until, she says, "they just memorized the pen."

Non-traditional. Most of Liz's programs do not have specific plans but rather utilize her overriding beliefs and concepts to work with children in all the programs given the diverse issues that many children experience. Liz works with the children looking for teachable moments and she plans the lesson according to the specific day. As she says, "it depends on what their needs are in the moment and what opportunity you can catch to teach them." She explains that if you plan too strictly, things might get "off shift" if an issue comes up, so she utilizes this as a learning opportunity for the children and helps work them through it.

In her horse program, she first sees where the child is at and then she teaches them how to make their horse stop and how to make it go. She notes she does this with any child "no matter what ability level...even if they can't wiggle their feet" she provides an alternative such as tapping her hands twice to help children with a sense of control over the horse and the activity. Her camp program is more structured as it is a larger group of children although it is not programmed fully.

Liz expressed that although her programs are different, the overall goals are similar, as she would like the children to be "independent and feel more in control of their lives." The 
primary goals are to increase independence, acquire critical thinking skills, decision-making skills, problem solving skills, and for the child to initiate activities. She notes:

I would like my kids to have fun...the only way they are going to...enjoy themselves or be happy is if they can learn to control some portions of their lives and none of them know how to do that other than in negative ways.

Liz's programs challenge children as she wants children to know what they are capable of and that she and her staff believe in them. Liz described that her short term expectations are for children to "cope with what we are throwing at them, because what we are throwing at them is pretty overwhelming." She does not try to put demands on the children at the beginning because they do not know her. She explains, "why should they trust anything I say? Where is my credibility in telling them something?" Liz expects that children will slowly learn to trust her and she builds "trust and a relationship," something she says, "I don't think most people think about."

She does not to give children directives but when children make decisions she provides reinforcement for them to acknowledge their independence and decision making skills so in the end they will be able to direct themselves and be independent. She likes the children to figure out challenges on their own and she waits however she primarily plays to children's strengths rather than focusing on negatives of challenges they may experience.

\section{Admission}

This section examines how the service approaches differ when it comes to admissions, funding, and costs.

Traditional. Applied Behaviour Analysis is for children with Autism Spectrum Disorders. Families hear about ABA services through the government because, as Rachel says, "when you have been given a diagnosis of autism, you automatically are entitled to this 
funding." In Ontario, children diagnosed with ASD automatically get put on the waitlist to receive funding for ABA services. The waitlist is roughly four-years and once children are at the top of the waitlist they are able to receive funding from the government and their ABA services can begin.

The organization Rachel works for keeps her informed about funding changes and agreements. Ontario's funding agreement works on a six-month basis where every six-months children are reviewed. The process involves weekly assessments, graphs, and data to be submitted which provide a breakdown of each goal and how quickly the child is achieving their goals. In addition, a DVD video session is submitted and the organization funders review everything. The outcome from the review is: (1) the child is making continuous gains and is eligible for another six month period of funds or (2) the child has plateaued or not making gains sufficiently and their funding will be eliminated.

Children receive funding from the government for 20 hours of ABA services a week. For a three-month period children are receiving the funding amount of "roughly around $\$ 10,300$ " which is based on " 20 hours at 39 dollars an hour" and "anything over 20 hours is out of the parents pocket." Her clients are all in the direct funding program and hire their own private therapists from the organization.

Non-traditional. Families hear about Liz's program through word of mouth, her website, and brochures which she sends out to disability service organizations and providers such as SickKids, Children's Treatment Centre, Bloorview, and Occupational Therapists. She said she is "pretty well known in disability world" and for example said, "a new parent the other day said this therapist recommended you, she said you were really great." 
The admission for Liz's programs is for "anybody and everybody" and as long as she feels she can support the child's physical, emotional, and psychological needs. "I can't think of anybody we have ever turned down," she says. Prior to beginning programs, she meets with families to communicate about their children and their wants and needs and says "behavioural issues are not a problem for us as long as the parents are willing to sometimes pay for the extra support if they need." She also notes that certain programs are not appropriate for every child such as it might be too strenuous for some to attend riding camp.

Liz's programs are private and receive no direct funding. Her funds come from her clients (i.e. families). Some families receive special funding from agencies for summer camp but they have to apply themselves. Each program varies in cost given that they differ in length, time, and activity. To provide some pricing examples: the biking and gym programs cost $\$ 30.00 /$ hour, the dog program costs $\$ 40.00$ / hour, the riding program costs $\$ 50.00 /$ hour, and the camp costs $\$ 100.00 /$ day. All children pay the same amount however she notes, "in summer camp...[some children]...I know can't afford to come, so we don't charge them... each summer I try to take two or three kids."

\section{Benefits}

This section explores the way in which each provider perceives the benefits of their programs and goals for the children.

Traditional. When recalling Rachel's perceived benefits of ABA for a child Rachel rolled her eyes and stopped. She explained that teaching a child about a pen and how to pick up a pen is transferable for children in school settings. She notes teachers will ask for children to go get a pen and the child will be able to go get it independently and if a child does not have a pen, they will be able to request to the teacher and say that they do not have a pen. ABA also benefits 
children in developing their behaviour management skills, communication, social skills, daily living skills, and emotional regulation.

Non-traditional. Liz's promotional material suggests the variety of programs benefits children as they provide opportunities for success while concurrently challenging children and increasing emotional, physical, and cognitive development and well-being. The programs promote health and fitness through activities. Group programs provide an inclusive environment for children where they are able to develop a sense of belonging and where children are understood for their abilities and contributions. In addition, in this environment children are appreciated and friendships are developed.

Liz says that at other programs children "would just be sitting at a table" whereas at her programs she wants children to learn from "doing" and she has expectations for the children because she wants children to "come out of our program, believing that somebody thinks they are capable of doing something." Liz notes her recent dog program benefits children and families in terms of cost and time savings as typically an autism service dog would cost "about $\$ 25,000$ " and involves long processes of eligibility and waitlists.

\section{Providers Perspectives on Children's Views and Experiences}

This section explores how each service-provider perceives what and how children view and experience their programs, goals, and the service provider.

Traditional. Rachel explained the children are young academically and cognitively which she sees as hindering their understanding of the program. She believes the children she works with are not aware of their goals or expectations throughout the program. She explained many children do not enjoy $\mathrm{ABA}$ at all and they display this through their behaviours. When discussing how Rachel perceives what the children expect from her she immediately replied not 
in terms of the children's expectations but rather she directed her answer to her bigger concern, thinking of what, "my families, they expect that the child will..."

When inquiring about how Rachel believes the children see her, she notes “...they see me as a person that comes in, we do work, we play, there is fun times, happy times, but there is also times when I get angry and upset and there is a negative consequence." She further explained how she believes the children see all the professionals who work with them as "...person A comes over...we do certain activities...certain programs, and then person A leaves. Then person B comes in, does the same thing, and then they leave."

Non-traditional. When recalling how Liz perceives children's initial expectations of her she said, "I don't think that they have any idea, I think they come in and expect we will just tell them what to do, because that is every program." Liz believes the children are nervous as many people are when they get introduced to a new situation but "I think it is a million times worse for our kids because they are such control freaks because they have no control over their environment." Liz says, "I don't think kids with autism know how to have fun, the world is too overwhelming and scary."

She perceives that because of the way that some of the children have been treated in their homes they think they are the "centre of the universe." She sees many of them trying to manipulate her to doing things for them because they have learned they have so much power in their homes. She does not let them take advantage over her in the programs and instead she tries to assist them and says "they can take it in a positive manner, in a responsible manner." She believes her children feel good, and the issues that she encounters with them initially are shock because she pushes her children believing they are capable and she wants them to feel that way. 
When discussing whether children enjoy or do not enjoy the program, Liz explained that the only program children sometimes do not like initially is biking and the horses "because they are terrified" and some children feel "so much pressure" from parents because "every parent wants their kid to ride a two wheeler." She said most children expect and do have fun. She believes most of the children come and understand what activities they are doing and enjoy them but it differs from child to child. She also notes it is hard to understand what some children want or feel because when children are stuck sometimes and do not know what to do, they have trouble answering when she inquires about what they need to do or where they need help. So she does not necessarily know how children view things.

Liz believes that children in her program see her as "lots of different things." She builds a relationship with the children and instead of presenting herself as a teacher she presents herself as "someone who is there to help them problem solve and support them...it's a coaching thing more than a teaching thing." She notes she offers children "information and I try to help them deal with how they process it and execute it." She says she tries not to create a hierarchy with the children but she believes she has the validity to make requests when she needs something. She notes, "there are times I have to put my foot down because they need someone to lead them." Liz believes that to the children "I am just one of them... we goof around...everything I do with them...I work with them, I say we have to get the barn done, not you guys have to go do the barn..."

\section{How the Providers Approach Challenges with Children}

This section explores how each provider approaches the challenges that they experience with children throughout their programs. 
Traditional. Rachel explained verbal children inform her when they do not like what they are doing through oral communication. Non-verbal children express through body language and their behaviours, which she says, “... could be escape, physical reaction where they are hitting you or pinching you, it could be throwing things, it depends on the child." ABA follows behaviour protocols for when a child displays negative behaviours such as hitting through using Antecedent Behaviour Consequence ( $\mathrm{ABC}$ ) data. The $\mathrm{ABC}$ data associates negative behaviours to behaviour consequences such as "if a child hits then you block, you ignore, or you remove the child, or you could be taking the preferred reinforcement away that they were looking for.”

Rachel also conveyed that $\mathrm{ABA}$ has reinforcement criteria and protocol to instruct the program and motivate the children. ABA begins with an instruction and once the child completes the instruction the ABA specialist rewards the child with praising them with either "a tangible reward or edible or a praise or a song, whatever they like, so you are pairing a non-preferred with a preferred." ABA uses this method to teach children "by doing something that they do not really like, they ultimately get something that they really really love."

Non-traditional. Liz notes she works with challenges differently for each child. She believes that few of the children that she works with are badly behaved because "they always have a reason for their behaviour, and most of it is because they are afraid." She further explains that "half or $75 \%$ of the time we are the reasons" and notes, "[then]...you have to fix something...that's the philosophy around here." When she experiences challenges with children being nervous or do not want to do something, she states that she works them:

Past it...we give them a mini horse...we give them control. So if they are afraid to get on the horse, we let them work the horse on the ground...[the children]... realize that they can control the horse on the ground, and a lot of the time they can do it by themselves... and they are happy. And we do the same thing in bikes, we find them something that they can ride easily and then we work with them step by step. 
Liz expressed her programs to be different and creative and notes motivation is intrinsic in all of her programs. When the children are motivated they learn "in one second." In the bike program, if a child does not want to ride a bike, they find an alternative, such as a step-and-go or a scooter so they adjust. She also uses her energy to motivate children and build drive. She does the opposite to help children calm down and relax. For example if children are misbehaving, many others give time outs however Liz will do the opposite and shut down her body energy. She said this lowers the children's drive, and she finds it "puts it on them" and as a result they internalize it and understand to switch activities or behaviours.

\section{Interaction and Collaboration with Families}

This section examines the manner in which each provider interacts and collaborates with families. As families are diverse, providers collaborate differently depending on the family.

Traditional. Rachel notes some parents appreciate being involved and share their requested goals whereas other parents do not. Parents' goals may be able to be brought into the program "as long as it can be quantified," but she adds, "I also have restrictions ... [and] these are certain things I need to do to qualify for funding."

Rachel has expectations for families in terms of daily living skills such as toileting, feeding, and spontaneous language. She notes, "parents can be frustrating because sometimes they don't want to follow through on certain things... [and if parents]... are not consistent [with the child]...they are never really learning to the full potential." She does not expect families to follow through academically with ABA because "there are certain strict principles and teaching methods that you need to follow," and specialists should only be providing those aspects.

Throughout the service Rachel expressed that she shares the children's success with the families. For families who are finished with funding, Rachel and the families come up with an 
agreement in order for her to stay working with them where they can afford a certain number of hours to work with their budget.

Non-traditional. Liz interacts with families differently depending on the program and depending on the child and parents needs. If the families want to collaborate and work with her and her staff, she will. Liz works with families initially prior to coming to each program as she meets with families and has dialogue to see which program they are interested in. This assists her to see if a specific program is a good fit for the child and how Liz and her staff can meet their needs. Liz does not like "pushing my programs on parents" and she wants parents to "see what it is and decide." She notes, "I am not sure people always understand what we do, so the ones that seem to understand seem to stay." She informed me many children and families have been with her for five years and others for twelve years. Although she recognizes the challenges as she states some parents do not realize that children benefit when they are in the program for longer as it takes time to adjust, learn, grow, and develop.

Liz notes, "if you ask the parents what the goals are for the children in camp, everybody without the exception...[will say]...I just want them to have fun." She informed me "families really struggle to tell you what they want" which she believes is because:

Parents are so overwhelmed, they don't think about that...because they do have so much to deal with and it is so overwhelming for them I think they are happier if they can leave...[the]...decisions up to the professionals, people that they trust.

She notes most parents trust professionals because of their titles and notes "people have no sense of discrimination or judgment so if they hear there is a great program for their kids they send them to it." She provided many examples of parents she has worked with who had spent money on therapies and believes many think, "the more you charge the better you are." She recognizes 
that it is challenging as she notes, "parents...don't know what is right and what is wrong and what is good...they are afraid not to try something in case it works.”

Liz informed me that she is upfront and honest with parents. For example, she notes if a parent says something that she does not necessarily agree with she sticks up for the child and informs the parent that "[the child is]...not going to ride a bike without training wheels unless they want to, so why don't we find something that they can ride that is motivational for them." She also does not tell parents that they have to work on anything with the children because she understands the complexity of their lives. She notes "if you are a parent to one of these kids you just have to get through the day, you have to put food on the table, go to your job, get your kids organized" and recognizes the "emotional power struggle" that parents face when they attempt to teach their own child because it is challenging for them to be "objective and that's not their fault."

Liz does collaborate with families in two of her programs. She works with children with ASD and their families in their homes and provides a dog-training program as an introductory for the child and the family. She also collaborates with a family for whom she provides private consultation and support for them and their two children. She plans and supports the family and is in contact with them frequently.

\section{Interaction and Collaboration with Professionals}

This section explores each provider's account as to the manner in which they interact and collaborate with other professionals.

Traditional. Rachel works with a number of professionals from her organization. The organization and her supervisors keep her up to date on policy changes and provide her with resources and opportunities to attend professional development workshops. She primarily works 
with a team that includes a senior therapist and a psychologist. The senior therapist and psychologist oversee her work and supervise her. The team shares information including children's success and as well as challenges that Rachel may encounter. She benefits from the team meetings and enjoys working with them as they enhance her practice in many ways. She notes, "we can get stuck in a rut, and sometimes you have an outside perspective that comes in...[and]...you can talk...brainstorm...[and]...come up with really interesting ways of teaching a child."

Non-traditional. Liz primarily collaborates with other professionals while working with the family who hired her to work with their two children. She informed me she does not enjoy collaborating with other professionals typically because she believes many other professionals in the field don't use the word relationship or think of relationships in terms of the children as their clients. She notes, “I can't collaborate with anybody that doesn't want to spend enough time with our kids." She notes she does not agree with many of their approaches and thinks the field and other professionals in the field are "one-sided and narrow-minded." She has sent back many communication disorders assistants that are sent to work with her, the children, and the family, because they do not work well with them. She said they did not get to know the children and that "they think since they are professionals they can just come in and be competent."

Liz recalls professionals come in once every six months, observe the children, and take notes. She said, "they follow our kids around and stare at them while they are eating and they are in their faces and they are just like bugs in a microscope." She notes the professionals will use any program based on what they observe from their little knowledge of the child instead of getting to know them. She then exclaimed, "you can't...[suggest]... a program and expect someone to learn from it, but that seems to be the predominant thought process these days in our 
field." She does not agree with this as she customizes each program and her approach individually for each child.

She recalls with one of the children not responding to a program as she noted the speech therapist, to increase the child's verbal communication skills, was withholding the child's lunch and making the child request each piece of lunch and then the speech therapist would hand it to the child. She noted, “...[the speech therapist]...just thought he was being stubborn and badly behaved," to which Liz responded in favour of the child and said, "would you want to eat lunch? Plus, where is my independence?" She believes her values do not line up with many other professionals because she wants the children to feel more in control and feel independent and notes if the children cannot then "why would they want to learn anything."

\section{Education and Experience}

This section explores the provider's information and perspectives on their approaches through their educational background and experiences.

Traditional. As a primary ABA specialist, Rachel has background education with an Early Childhood Education (ECE) Diploma, an ABA Certification, and a Resource Teacher/Early Interventionist Certification and receives ongoing professional development from her organization. She states, "the best thing for me was my ECE and my Resource Teacher/Early Intervention programs, for me those were my two biggest benefits."

She perceives an educational background as necessary. She also states "experience trumps the education, because every child, no matter what the diagnosis is, they are different." She learns from every child and explained, "there is no book that will tell you how to deal with an autistic kid, every autistic kid, they write their own book.” She explained, “...you can go to school for this...read...study ...do all of this ABC data... which is great, but hands on is [better]." 
Non-traditional. Liz has a Physical Education Degree and is a certified Life Skills Coach. She also has extensive experience working with disabled children and youth in group facilitation and has completed courses on animal training and therapy work.

When discussing the field and training she perceives education and experience as equal however states, "there is no specific training for this kind of stuff." Her program is unique, "where would I even go and take formal training in this?" She notes she has books and DVDs and on primary topics of disabilities, dogs, and horses and utilizes this through her programs. She notes, "we are all still learning here...[because]...we are working with kids that push our buttons.”

\section{Challenges and Limitations they Experience with the Program and Field}

This section explores each provider's perspectives of the challenges and limitations that they experience in their program and the field overall. It also describes what the provider sees for the future to address challenges.

Traditional. Rachel used the term "drama" to describe the issues she experiences and the politics involved in the field in terms of waitlists, funding, and program overall. She notes waitlists are extremely long for children to receive $\mathrm{ABA}$ and consequently, "by the time children do receive funding, it is almost too late...there are certain things that are engrained and set in.”

Rachel states there have been funding cut backs that have affected her ability to assist children. Some children are only able to have funding for six-months whereas other children are able to have funding for two-years. She is troubled by this and the field and she notes, "it is really sad... what happens after two years... are they not considered on the spectrum...do they not need support after that?" She states subsequent the program children are suppose to "go fit into 
society." She goes on and explains, "[but] they do need support, but if you are not financially stable...[you won't]...get support... and everything that was achieved could be lost."

Rachel notes multiple limitations of how rigid the ABA program is which limits children's success. For example, a mandatory component of ABA is that 10 hours of ABA a week must be done within the hours of 9-3, Monday to Friday. She notes ABA specialists are not always allowed into educational institutions to support the children and as a result the child "has to stay home and do one-on-one work... [instead of in the]...classroom and working with the therapist...[as]...part of the school and the community." She further explains that consequently this hinders their ability to transfer skills as children "are sitting at home at a table and...doing all these robotic things but they don't know how to take that information...into the classroom." She informed me "sometimes not all...[children]...benefit from that approach...even though they are in the program." She understands how children are diverse learners and some are "not that kind of learner where they need to sit at the table and have intense stuff done...over and over and over again."

Rachel informed me despite challenges she will continue to work in the ABA field, as she loves the work she does. Ideally she would like to use components of ABA and combine it with other techniques and approaches in order to "create an optimal learning environment" for children such as floor time and play based therapies.

Non-traditional. Liz experiences challenges in relation to competition, funding, and lack of recognition and training in her program. She notes that some people have "a hard time in my program because there is no prescribed program" and other programs that are offered are not doing the type of work she does with the children in her programs. Liz recalls that there has been an increase in other programs that are available for children, and she experiences challenges in 
relation to competition, especially in terms of summer camp. For example, she does not offer bussing services and sees this as an issue as other camps "pick your kid up at the door at 7:30 and they deliver them back at 5:00, well who is not gonna jump on that?"

Similarly, Liz recognizes the challenges of funding as not a lot of families can afford private programs. As a result, many turn to $\mathrm{ABA}$ funded programs from the government. These challenges come from systemic and dominant ideologies as most funding goes solely to ABA services. Liz discusses how primarily there is education for working with disabled children with Autism Spectrum Disorders but notes “ABA isn't the only way." She notes her programs are different from ABA because she cares about how children feel and uses their capabilities to build on their skills whereas "ABA is all about each skill but it is not necessarily about the underlying, how [the children] feel." After she explained the delivery of ABA is, "they just sit there and feed and teach." She notes this process is "demeaning" and sometimes might not benefit children as they may be able to get dressed and complete routines however they might not have control since no one has provided them with the opportunities to make decisions.

Liz described multiple visions for her future despite challenges she encounters. She described how a child in one of her programs recently created a movie trailer and filmed herself working with the horses and dogs and illustrated in the trailer how they helped her develop. "I wish they could do more of that," she stated, as it was out of the box and was helping the child with her passion for acting. In addition to making changes with children in her programs, she hopes to make changes within the field as a whole. She believes "people in our world need to learn from a lot of non-traditional unrelated sources.” As she explained there is a lack of formal training on what she provides and she notes "don't you think it is sad that in our world of disability there is no education in this area?" She explains it is frustrating as the only reason for 
this is because the government has decided to invest primarily in ABA and ignore alternative approaches.

\section{Conclusion}

This chapter provided the data collected from the participants through descriptive narratives of each service-provider. Through examining each provider perspectives on the topics

of their service, the programs plans, goals, and expectations, the admission process, the benefits, and their perspectives on children's experiences and views. In addition, examining how each provider interacts and collaborates with families and professionals, their education and experience background, and the challenges they experience with their program and the field overall, the differences and similarities begin to appear as the sections depicted each serviceproviders voice and perspective. Having said this, the following chapter offers a discussion on the findings presented above in relation to the primary research question of: which approach comes closer to ensuring disabled children's rights, well-being, and interests? 


\section{Chapter 6 - Discussion}

\section{Introduction}

This chapter explores the data presented in the previous chapter through a discussion of themes that I identified in my data. From a close reading of the narratives drawn from the providers' perspectives, I have organized this section along three themes that underpin their different approaches in order to answer the research question of: which approach comes closer to ensuring disabled children's rights, well-being, and interests? I recognize that the information presented is not exclusive to these themes as the issues are often intertwined and overlapping. However, for reasons of clarity and to illustrate my argument, I have chosen to discuss my findings under three themes presented as the following binaries: (1) Silent Actors/Social Actors, (2) Taking Control/Fostering Control, and (3) Formal/Informal Approaches.

Subsequent to presenting the themes on Silent Actors/Social Actors, Taking Control/Fostering Control and Formal/Informal Approaches, I will present interesting and surprising findings such as common challenges that both Rachel and Liz experience. To conclude this chapter I suggest that the traditional approach represented by Rachel is provided to produce the "idea of a universal child" whereas the non-traditional approach practiced by Liz is provided to foster "the child as an individual" and return to my primary research question of: which approach comes closer to ensuring disabled children's rights, well-being, and interests?

\section{Silent Actors/Social Actors}

The binary of Silent Actors/Social Actors draws from the theoretical underpinnings that inform this research study and from the literature on traditional and non-traditional approaches to services for disabled children. Depicting children as silent actors derives from dominant ideologies, which tend to perceive children as incompetent. As a result, children often are 
silenced and denied the opportunities to voice their opinions, thus they are depicted as silent actors (Matthews, 2007; Tisdal, 2012). Literature suggests disabled children's voices and perceptions are not incorporated into children's services but instead others speak for them such as professionals, researchers, and parents (April et al., 2009; Gasalberti et al., 2006; Grindle et al., 2009; Hayward et al., 2009; McPhilemy \& Dillenburger, 2013; Steege et al., 2007).

On the other hand, depicting children as social actors derives from critiquing dominant ideologies and recognizing children as competent citizens who are experts on their own lives. Seeing disabled children as social actors stems from acknowledging children's rights in terms of having the abilities to express opinions in relation to aspects that affect their own lives, such as the services they receive (Iannacci \& Graham, 2013; Matthews, 2007; Tisdall, 2012). This section demonstrates how Silent Actors/Social Actors emerges in both approaches.

Throughout Rachel's approach, children are frequently dismissed and may be seen as silent actors as adults speak for them. This may be seen when discussing what children expect from Rachel and the Applied Behaviour Analysis (ABA) program, Rachel immediately answered in terms of "...my families, they expect that the child will..." and it was the families' expectations that became prominent instead of what children wanted. Alternatively, when examining Liz's experiences in working with children and families, it appears that Liz acknowledges children to be social actors in their lives because she seemed to challenge families when parents were pushing activities for their children. A good example of this is when Liz stated, "[the child is]...not going to ride a bike without training wheels unless they want to, so why don't we find something that they can ride that is motivational for them." This implies that Liz puts children's needs first prior to the families and acknowledges children's participation in their programming, as she wants them to be involved. 
Rachel expressed that children in her program are rated low cognitively and academically and suggested because of this, they do not understand her program. In communicating her perceptions of how children feel about her and other professionals within the program she stated, “...person A comes over, we work we do certain activities, certain games, certain programs, and then person A leaves, then person B comes in, does the same thing, and then they leave." This may imply that Rachel perceives disabled children as silent actors given that she does not recognize children's competencies and that children do not have the ability to distinguish adults and the program overall.

A different perspective of disabled children emerged from Liz's responses when she stated in her experience most children come in, understand, and enjoy the programs and their activities. She acknowledged that all children are different and as a result, sometimes it is challenging to understand how many feel. Liz stated that children might see her as "lots of different things." This may suggest that Liz perceives disabled children as social actors as she accepts children's differences and acknowledges that she does not understand how children feel sometimes and cannot speak for them.

When examining the collaboration and evaluation process of each approach other differences emerge. Once again it may be seen that Rachel's approach dismisses children and results in children being perceived as silent actors whereas Liz's approach involves working with the child "in the moment" given every day may be different and every child is different. For example, Rachel's approach is to collaborate with other professionals only when she is experiencing a challenge with a child. The professionals work together to brainstorm new ideas however, the child is not included in this discussion and as a result children are silent as their perspectives are not accounted for and they are spoken about by others. Similarly, Rachel 
indicated that children are evaluated based on quantitative data written about them. With this in mind, it might mean that children are viewed as objects, given that in order to continue to receive funding, children are reviewed and then may be dismissed. This process also suggests children as a sole number in the ABA program, as they are not a part of this process but instead only appear in the notes written about them.

When it comes to collaboration and evaluation, Liz's approach appears to recognize children as social actors as she is guided by values that promote relationships with children and, which she considers to be necessary to the programs. Liz critiqued collaborating with other professionals given that many professionals do not hold the same values as her, she notes to many professionals, “...[children] are just like bugs in a microscope.” She noted the instance when another professional was withholding a child's food in order to have the child increase their verbal skills. Liz said, as she recognizes putting children first, "would you want to eat lunch? Plus where is my independence?"

Similarly, the manner in which children are evaluated in Liz's program may indicate another way in which children may be perceived as social actors. Liz expressed she does not typically evaluate children and did not indicate any specific process for evaluating children. Instead, she noted that she works with children on whatever they want or need each day. In addition, the notion of social actors is present in her approach in which as she expressed when children are having challenges she waits for them to work through it and or supports them through it. She also noted she does not focus on the negatives of these challenges but instead recognizes children's competencies and focuses on their strengths as they move forward with alternative methods and solutions for activities. 
From this discussion it may be seen that disabled children appear as silent actors in Rachel's more traditional approach. This was seen as Rachel does not provide children the opportunity to speak in matters that relate to their own lives and does not view children as competent and as a result may be seen to infringe on disabled children's rights. Alternatively, Liz's more non-traditional approach appears to acknowledge children as competent as she recognizes children's differences and utilizes this knowledge within her approach and as a result it may be seen that children are seen as social actors.

Along with Rachel's approach that might view children as silent actors, the notion that children are being controlled is also suggested. Similarly, along with Liz's approach, which views children as social actors, the notion that children are fostered to take some control in their life is suggested. This will be discussed under the theme of Taking Control/Fostering Control in the following section.

\section{Taking Control/Fostering Control}

As children appear to be viewed as silent actors in the traditional approach and social actors in the non-traditional approach, the binary of Taking Control/Fostering Control is another theme that emerged from my findings. Taking control of children derives from the theoretical background and literature on traditional approaches for disabled children. Hierarchies from adults exerting their power over disabled children have resulted in disabled children being frequently silenced in their services. This has caused ethical dilemmas given that adults are controlling children's lives and speaking for them (Glynne-Owen, 2010; Iannacci \& Graham, 2013; Ladd, 2005, Matthews, 2007; Tisdall, 2012).

Fostering control with children stems from the theory and literature that critique dominant ideologies such as non-traditional approaches as it suggests recognizing disabled 
children as equal through acknowledging power imbalances. This may be done through alternative manners, such as fostering control with children and advocating for rights for disabled children to be able to participate and have their interests considered. Similarly, disabled children should not have to conform or be controlled by others (Glynne-Owen, 2010; Iannacci \& Graham, 2013; Ladd, 2005; Matthews, 2007; Tisdall, 2012; Vandergrift \& Bennett, 2012). Having said this, this section explores a discussion on Taking Control/Fostering Control by illustrating Rachel's approach and Liz's approach.

It may be seen that the manner in which Rachel's traditional approach is delivered is an attempt to control children. This was apparent through Rachel's explanations of her program in many ways. The delivery of Rachel's program is based on goals of the Assessment of Basic Language and Learning Skills (ABBLS) guidelines. ABBLS is framed around children having to complete each step of the goals in order to move on to another step. Control over children was demonstrated in the delivery of the program as Rachel insisted, "you are going to learn about this pen...if it takes you 10 hours...every session you are going to learn about this pen, 5 minutes, 7 minutes, day in and day out...until they just memorize the pen.” As these goals are predetermined, it appears that children are almost always being controlled as the program is based on the goals and on Rachel teaching the children in this strict format.

Liz's approach is to deliver a program in a manner which appears to provide opportunities for children to have control over their lives and thus to empower children. This was illustrated throughout Liz's values, which she expressed as recognizing the lack of control that children have in their lives. She noted, “...I think they come in and expect we will just tell them what to do, because that is every program." Instead of this controlling approach, Liz suggests that children should be able to exercise some control their lives. Instead of repeating the same 
sessions and fixating on children's negatives in order to move on with children such as Rachel's approach does, Liz provides alternative solutions for children and plays to children's strengths. For example, if a child is unable to wiggle their feet to make a horse move, Liz illustrated she provides an alternative solution, such as tapping her hand twice. Liz's rationale for this is so the child will feel that they are able to be in control of the horse.

The manner in which Rachel and Liz motivate children and how they approach challenges with children may also be seen to demonstrate the difference between taking control over children and fostering control with children respectively. Rachel utilizes children's interests to motivate children, which although is recognized to be a positive aspect of ensuring children's rights (Vandergrift \& Bennett, 2012), the manner in which Rachel utilizes children's interests may be seen to concurrently exert her power. This was illustrated when Rachel expressed, "by doing something that they do not really like, they ultimately get something that they really really love." This suggests that Rachel is aware that children do not like the program but disregards their preferences. Similarly, it appears that children's preferences are bound to Rachel's terms as in the program's behaviour protocol she has the ability to take away the child's motivational and preferred item. This implies that Rachel exerts her power as she always has the ability to control children when they do not comply and do not behave in the manner that children are expected to behave.

Liz approaches motivation and challenges with children by another method that may be seen to demonstrate how Liz fosters giving children control. Liz stated she does not plan programs and sessions specifically because she recognizes the challenges that disabled children, like all individuals, may be experiencing given that one day may be different from the next. Liz expressed how motivation and children's interests are inherent in her program, saying that when 
children are motivated they learn "in one second." Liz expressed that sometimes she experiences challenges with children in terms of their behaviour however she stated that "half or $75 \%$ of the time we are the reasons" and noted, "[then]...you have to fix something...that's the philosophy around here." Having said this, she approaches challenges differently with each child and noted most of the time it is because children are nervous. However she fosters this through providing them with control, which is demonstrated as she recognizes each child's abilities and works through them with her support. If a child appears to be too nervous to get on a horse, she provides a miniature horse and the child works with the miniature horse on the ground so they slowly come to feel comfortable and confident in their abilities to control and be with a horse. She wants children to feel capable which is why the values and goals throughout her programs are to help children gain independence, critical thinking skills, and decision making skills while she builds relationships with children. All of these components imply that Liz's approach fosters children with some control of their daily lives.

This section explored a variety of examples, which demonstrated Rachel's approach to taking control over children, especially given the goals are predetermined and the ways a child must complete a section in order to move on. Where are children's rights and interests if they have to do something so repetitively and why are they not able to control any aspects of their sessions? With this in mind, I suggest this is because of the formality of Rachel's approach. Whereas in Liz's approach, she employs fostering control with children as she works in the moment and focuses on children's strengths. Children appear to help drive the program as Liz works within their comfort levels and this leads me to suggest this is because her approach is informal in nature. The following section will discuss the theme of Formal/Informal Approaches. 


\section{Formal/Informal Approaches}

The binary of Formal/Informal Approaches is the last theme. This theme was chosen based on the theory and literature on traditional and non-traditional approaches. Identities of norms are based on social constructs. As mentioned earlier, the formal and dominant approach to disability is based on a deficit-based approach, which defines and categorizes disabled children into their deemed deficit of category (Iannacci \& Graham, 2013). The ABA approach is formal and rigid in nature and attempts to normalize disabled children with Autism Spectrum Disorders (ASD) (Glynne-Owen, 2010; Ladd, 2005).

The medicalization of the definition of Autism Spectrum Disorders and as a result, the creation of the structured Applied Behaviour Analysis approach for children with Autism Spectrum Disorders may be seen as contradictory. How can ABA, an approach that is so rigid in structure actually be effective for children with ASD when ASD presents itself so differently in children (Glynne-Owen, 2010; Ladd, 2005)? Similarly, instead of normalizing disabled children, and creating a homogeneity of disabled children, we may instead accept disability as diversity and may want to approach services with flexibility and in an informal nature (Glynne-Owen, 2010; Iannacci \& Graham, 2013; Ladd, 2005; Matthews; 2007; Tisdall, 2012). This section will explore how the theme of Formal/Informal Approaches emerges within Rachel and Liz's approaches.

Rachel's approach appears to be formal in nature as ABA derives from the dominant ideology perspective and a child's diagnosis drives the program. This may be seen throughout the admission process, delivery process, and evaluation process. Rachel expressed that upon diagnosis of ASD, children are automatically eligible and put on a waitlist to receive ABA services and funding. The delivery of ABA may also be seen as formal, as Rachel expressed, 
"ABA is very robotic" and she noted "...[the sessions] are all the same...everyday in a certain way, with a certain reinforcement schedule." Similarly, the evaluation of children is formal as well. In order for children to receive more funding and continue with the ABA program, children are evaluated in each session, and after six months, a board reviews the child's progress or lack of progress.

Alternatively Liz's approach appears to be informal and as a result her programs, are flexible in nature. This was illustrated when Liz expressed she accepts children with all differences and disabilities and selective disabled children are not excluded from her program. Instead of the children's diagnosis driving the program, such as Rachel's approach, it may be seen that children drive the programs in Liz's approach. In addition, when meeting with families prior to beginning services, there is a dialogue to discuss which of the variety of programs would be best to meet the child's needs, and considerations are made as to which program or programs would be best suitable. Liz's approach appears informal and flexible because she understands that "you can't...[suggest]... a program and expect someone to learn from it," and therefore offers a variety of programs and customizes them for each child.

This section examined the theme of Formal/Informal Approaches by providing a variety of examples within both approaches. This interpretation suggests that the Rachel's approach/the traditional approach, is formal in nature given that a child's diagnosis drives the programs and children have predetermined goals set up for them. Liz's approach/the non-traditional approach, is informal in nature given that she accepts all children and is flexible in her delivery process, as she customizes each program to each child. As I have discussed how each approach emerges through the binary themes of Silent Actors/Social Actors, Taking Control/Fostering Control, and 
Formal/Informal Approaches, I will now present some of the interesting and surprising findings collected.

\section{Interesting and Surprising Findings}

There were a number of fascinating findings from this research study. One interesting finding is in relation to the challenges Rachel and Liz experience in terms of the limitations of their programs. It may be seen that both Rachel and Liz acknowledge limitations of their services but while Rachel experiences limitations due to the formality of her approach, Liz experiences limitations due to the informality of her approach. This section will discuss these interpretations.

There are a number of challenges due to the rigid structure of ABA from the admission process, to the delivery process, and the evaluation process, that Rachel mentioned which limit children in many ways. Rachel explained there are extremely long waitlists for children to receive funding. She said these waitlists cause issues because "by the time children do receive funding, it is almost to late...there are certain things that are engrained and set in."

Rachel also expressed two challenges with ABA's delivery process given that it is rigid in structure. The first limitation is that if Rachel is not allowed into a child's school to complete the mandatory 10 hours of ABA each week, children are forced to work at home, are segregated from their peers and the school community, and are unable to transfer skills to the school environment. The second limitation Rachel expressed is that all children are delivered the exact same program. Rachel indicated she recognizes the realities and diversity of children and rolled her eyes when speaking about the benefits of ABA. This was illustrated when Rachel expressed "sometimes not all...[children]...benefit from that approach...even though they are in the

program." She explained by stating some children are "not that kind of a learner where they need to sit at the table and have intense stuff done...over and over and over again." What can be made 
really interesting about this is that Rachel indicated she will continue to provide $\mathrm{ABA}$ as she loves working with children however noted ideally she would like to combine the ABA approach with other methods such as play therapy to "create an optimal learning environment." This suggests that Rachel is leaning towards alternative approaches as she recognizes the limitations of her program for children given that all children are unique.

Another limitation of the rigid structure of ABA that Rachel expressed was in regard to the evaluation process. She notes after the program, children are supposed to "go fit into society" regardless of whether they are successful in the program or not. She further explains this limitation, "[but] they do need support, but if you are not financially stable...[you won't]...get support...and everything that was achieved could be lost." Rachel's frustrations are troubling given that she is unable to do anything about these issues as they are mandatory components of the ABA program and the system.

Liz has also experienced challenges, and in her case it is due to the informality of her approach. Liz explained the government acknowledges and supports ABA and as a result there is funding for children in $\mathrm{ABA}$ and not for her approach/programs. She also states, "ABA is not the only way," is "demeaning," and instead believes "people in our world need to learn from a lot of non-traditional unrelated sources." This suggests that Liz acknowledges her departure from the dominant ideologies of society as it has challenged her services.

Another interesting and quite unexpected finding was about the manner in which Rachel and Liz both view education and experience. It emerged that they view many issues differently but on this subject they appear to be on the same page. Rachel and Liz both appear to perceive education and experience similarly as they agree education is useful and also note experience to be a more powerful tool. This was demonstrated when Rachel stated "there is no book that will 
tell you how to deal with an autistic kid, every autistic kid," because she added, "they write their own book." Similarly, Liz feels she learns everyday but commented there is no specific book or course that she could take about her work, so she reads all the time and learns everyday from the children. It appears that their perspectives stem from the formality and informality of the approaches. It is surprising that Rachel is involved with providing a service that is so structured when she acknowledges and critiques numerous limitations of ABA. Liz appears to still be focused on questioning dominant ideologies as she is providing programs that having challenges becoming accepted given that her approaches deviate from the norm.

\section{Conclusion}

This chapter established the manners in which the themes of Silent Actors/Social Actors, Taking Control/Fostering Control, and Formal/Informal Approaches appear in both approaches. I suggest that the traditional approach is delivered in attempts to produce the "idea of a universal child." The traditional approach perpetuates societal norms and as a result, homogenizes children and devalues disabled children's competencies. On the other hand, the non-traditional approach is delivered in an attempt to foster "the child as an individual." The non-traditional approach deviates from the norm as it recognizes children to be competent and equal to others and does not exert the provider's power of control over children.

The primary research question of this study was which approach comes closer to ensuring disabled children's rights, well-being, and interests? Disabled children's rights, wellbeing, and interests was operationalized based on whether or not children have a say in their programs, if children's preferences are taken into consideration, whose goals do the provider have in mind, and how the provider responds to challenges they experience. I suggest that the non-traditional approach comes closer to ensuring disabled children's rights, well-being, and 
interests. This is demonstrated as the non-traditional approach acknowledges children as social actors, fosters control throughout the approach, and does so in a manner that is flexible and informal as it recognizes the importance of children's individuality.

A child's rights framework, which derives from international conventions, may be seen to parallel the non-traditional approach (Vandergrift \& Bennett, 2012). Non-traditional approaches include collaboration, children's participation, and children's interests being taken into consideration (Gasalberti, 2006; Vandergrift \& Bennett, 2012). The framework also suggests all children to have the right to play and stresses the importance of children having active lifestyles, both components within the non-traditional programs (Vandergrift \& Bennett, 2012). Having said this, disabled children's rights appear to be incorporated in the non-traditional approach as their voices are taken into consideration given the acknowledgement of each child within each program. Children's voices are also promoted, which was displayed when the Liz stood up for children's wants and needs within the programs. As this chapter responded to the primary research question and discussed the manner in which the non-traditional approach appeared to come closer to ensuring disabled children's rights, well-being, and interests, the following chapter will discuss concluding thoughts about this research study and its contributions to the field. 


\section{Chapter 7 - Conclusion}

\section{Introduction}

This final chapter offers a conclusion to this research study. I first consider this research study's strengths and limitations. Subsequently I present implications and recommendations for future research, practice and policy, and the significance and contributions that this study may make to the field. This chapter finishes with a re-examination of the components in this research study.

\section{Strengths and Limitations}

This study offers both strengths and limitations. A limitation of qualitative research is that is not as recognized in some research communities given that quantitative research is more established and tends to be more compelling as numbers have been recognized to speak louder than words (Anderson, 2010). However, there are also strengths to qualitative research. It is known to be useful for forming and reforming policies and practice considerations. For example, qualitative research encompasses important aspects of research such as rich description, assisting in developing and examining strategies and learning methods, and in relating to current issues, and for these reasons, this approach was utilized for this study as I was able to capture the aspects mentioned above (Anderson, 2010).

The small-scale case study in this research study may be seen as a limitation (Anderson, 2010). Creswell (2014) suggests case studies to have four to five cases although two cases were purposefully chosen for a number of reasons. The amount of time provided to do this research study was minimal and a small number of cases was set to be a realistic goal given transcribing and analyzing data is known to be time consuming (Anderson, 2010). That being said, the small number also provides many strengths to this research study as examining two knowledge rich 
providers enabled me to have more of an in-depth understanding of disability services and specifically, the approaches utilized in the opposing services (Anderson, 2010). The small case study size may limit the generalizability of the research given that it is focused in one context and with two cases, although the results and strengths of this approach warrant disabled children's rights, well-being, and interests in their services to be worthy of additional exploration (Anderson, 2010).

The primary method of data collection, interviews, may also be seen as a limitation of this study. Anderson (2010) notes a researchers presence may hinder the participants' responses however having said this, the interview method was utilized given that the strengths outweighed the limitations. The interview protocol was in an open-ended semi-structured format which provided the service-providers with an opportunity to offer examples of their life experiences while expressing other issues or answers to questions and their responses revealed some surprising findings (Anderson, 2010).

The service-providers' perspectives were presented throughout the study and they were able to portray how their approach is delivered in a captivating and meaningful way. In addition, this method provided me with the opportunity to arrive at explanations and discuss interpretation based on the findings of the study and this provided validity of my interpretation and conclusion process. The in-depth detailed process throughout the study provided strong evidence of the process from findings and analysis to the discussion and conclusion, which is a strength for the study's credibility.

\section{Implications and Recommendations}

Future research. Through acknowledging disabled children's rights, well-being, and interests, this study questioned and challenged dominant ideologies that are apparent in 
traditional approach services for disabled children. This study indicated the manner in which the traditional approach of Applied Behaviour Analysis (ABA) appeared to not ensure disabled children's rights, well-being, and interests, and having said this, future research may want to continue to examine the ABA program in order to see if overlooking disabled children's rights, well-being, and interests is a reoccurring theme in this approach.

In addition, future researchers may want to investigate alternative types of methods to recognize disabled children's rights, well-being, and interests that could be incorporated into the ABA program and approach and how to employ these strategies. These include but are not limited to providing children with more options and choice within sessions, having multiple guide books instead one (such as Assessment of Basic Language and Learning Skills) that is used on children. Multiple books might help recognize diversity and incorporate alternative goals and activities that which may not produce a sole homogenizing group but instead promote individuality. In addition, future research might want to consider examining support systems put in place for disabled children subsequent ABA services and how and if children are involved in this process.

This study may have opened doors to research in an underserved field given that the availability of literature on disability-related services from this perspective is minimal. As the non-traditional approach appeared to come closer to ensuring disabled children's rights, wellbeing, and interests, this study is beneficial for future researchers given this topic warrants additional inquiry into alternative approaches for disabled children based on ensuring disabled children's rights, well-being, and interests. Future researchers may want to examine a variety of non-traditional approaches to see if disabled children's rights well-being, and interests being 
ensured are reoccurring themes given that it may help challenge dominant constructs and ideologies that are negatively attached to disabled children.

In addition, continuing with the theoretical framework of critical disability theory and the 'new' sociology of childhood, I suggest future research to include children's perspectives on this topic. Through interviewing children involved in both these approaches and programs, unique and original perspectives will be able to illuminate true accounts of how children feel about both approaches to service provision (traditional and non-traditional). Similarly, I also suggest future research is needed to explore disabled children's perceptions of what they would like to see incorporated into their services for the future. This will allow researchers, service-providers, policy-makers, and society to gain knowledge about what disabled children want, what they are interested in, what their goals are, and how we as society can work together to ensure disabled children's rights, well-being, and interests in designing future services for disabled children.

Future research might also examine additional service providers from both traditional and non-traditional approaches in order to have larger sample sizes and to have alternative contexts considered to see the theme of non-traditional approaches coming closer to ensuring disabled children's rights, well-being, and interests is a reoccurring theme when comparing to traditional approaches. Finally, to continue to bring forth the importance of disabled children's rights, wellbeing, and interests in the services offered, future research should keep questioning dominant ideological assumptions that perpetuate in our society which results in a negative and devaluing perspective on the discourse of disabled children.

Policy and practice. This study redefined how to perceive both traditional and nontraditional approaches and services for disabled children. There may not be a clear answer as to what defines best practice for providing services for disabled children however this study 
suggests an ambiguous explanation is warranted. In order to shift the negative discourse surrounding disability, policy-makers should question current services available for disabled children that derive from dominant ideologies based on deficit-based perspectives of disability and instead inquire stakeholders (i.e. disabled children and families) perspectives on services. Alternative approaches and services may warrant examination and consideration instead of automatically placing disabled children with funding for specific programs such as Applied Behaviour Analysis. Policy makers may wish to consider distributing funding to all service approaches equally given that not all children benefit from Applied Behaviour Analysis and in order to benefit all children not solely children with Autism Spectrum Disorders (ASD). This is critical if policy-makers are to support disabled children and take disabled children's rights, wellbeing, and interests more seriously.

This research study may enable professionals to consider a new perspective on both traditional and non-traditional approaches. This research study may assist professionals by helping them reflect on their current practices in order to recognize the importance of collaboration with children and including children in making decisions that impact on their lives. I suggest professionals research all possible services available for disabled children prior to recommending families to dominant service approaches. This research study may also benefit professionals as it enables a more holistic approach to working with children. This approach focuses on disabled children's strengths, health, and illuminates the importance of fostering relationships with disabled children and taking children seriously in order to promote and respect disabled children's individuality. As a result, the non-traditional holistic approach may be a more useful method for practitioners for ensuring disabled children's rights, well-being, interests, and services overall. 
Significance and contribution. This study is significant in many ways. It contributes to both the field of disability studies as well as the field of early childhood studies. To my knowledge this research study was the first of its kind as I was unable to obtain literature on the topic of disabled children's rights, well-being, and interests in their both service approaches. In addition, this study adds a unique perspective to the literature on disabled children and the literature on traditional and non-traditional approaches in a collaborative manner as it combines research in two scholarly fields into the question of disabled children's rights, well-being, and interests in their services. This study is also significant as it points out the lack of rights disabled children have in the services they receive and that there is much work ahead for research, policy, and practice consideration in order to ensure disabled children's rights are incorporated as international conventions recommends.

\section{Conclusion}

Drawing upon critical disability theory and the 'new' sociology of childhood, this research study recognized that although disabled children's rights, well-being, and interests are on the international agenda, they are infrequently mentioned in literature on disabled children's services. As a result, this research study examined traditional and non-traditional approaches through utilizing the research approach of a qualitative case study. By interviewing two community based service-providers for disabled children, this research study's purpose was to determine and illuminate which approach came closer to ensuring disabled children's rights, well-being, and interests.

An in-depth analysis of the findings presented many interpretations in the discussion that are worth noting. The traditional approach appears parallel to the literature in that disabled children are not recognized as competent, a hierarchy is present in the approach, disabled 
children are objectified as they are constantly being marked and assessed, and their goals are set out for them which is done seemingly to produce a homogenous group of children, i.e. the norm. The non-traditional approach diverges from traditional ideologies because it recognizes and fosters children's individuality through playing to their strengths, not having set plans, and advocating for relationships and striving for equality. In conclusion, I would argue that it may be seen that the non-traditional approach comes closer to ensuring disabled children's rights, wellbeing, and interests.

Going forward, an alternative approach may be taken from this research study in terms of presenting another way of viewing services. A shift in perspective enables us to acknowledge disabled children as social actors and as competent in making decisions. I recommend that policy-makers and practitioners take these components into consideration and recognize the importance of individuality and the various ways that disabled children learn while providing services and programs. By incorporating disabled children's opinions in an active and collaborative manner disabled children's rights, well-being, and interests may be respected so they may enjoy an active and meaningful life. 


\section{Appendices \\ Appendix A \\ Ryerson Research Ethics Board Approval}

\section{RYERSONUNIVERSITY}

\section{RESEARCH ETHICS BOARD}

To: Jaclyn Ederman

Masters of Arts - Early Childhood Studies

Re: REB 2014-131: Examining Traditional and Non-Traditional Approaches: Ensuring Disabled Children's Rights and Well-Being

Date: May 20, 2014

Dear Jaclyn Ederman,

The review of your protocol REB File REB 2014-131 is now complete. The project has been approved for a one year period. Please note that before proceeding with your project, compliance with other required University approvals/certifications, institutional requirements, or governmental authorizations may be required.

This approval may be extended after one year upon request. Please be advised that if the project is not renewed, approval will expire and no more research involving humans may take place. If this is a funded project, access to research funds may also be affected.

Please note that REB approval policies require that you adhere strictly to the protocol as last reviewed by the REB and that any modifications must be approved by the Board before they can be implemented. Adverse or unexpected events must be reported to the REB as soon as possible with an indication from the Principal Investigator as to how, in the view of the Principal Investigator, these events affect the continuation of the protocol.

Finally, if research subjects are in the care of a health facility, at a school, or other institution or community organization, it is the responsibility of the Principal Investigator to ensure that the ethical guidelines and approvals of those facilities or institutions are obtained and filed with the REB prior to the initiation of any research.

Please quote your REB file number (REB 2014-131) on future correspondence.

Congratulations and best of luck in conducting your research.

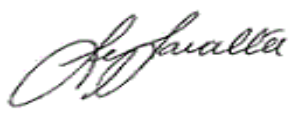

Lynn Lavallée, Ph.D.

Chair, Research Ethics Board 


\section{Appendix B \\ Email Proposal Script}

\section{Traditional Script}

To whom it may concern,

I am currently in the Masters of Arts, Early Childhood Studies Degree at Ryerson University. I am pursuing my Major Research Paper (MRP) for my Degree and am emailing you to inquire about possible participation in my study.

I am interested in looking at both traditional approaches (such as ABA) as well as the more nontraditional approaches. I am interested in learning how each service functions and through this would like to see how and if disabled children's rights and well-being are being met within the support and programs that children receive.

Having said all of this, I was wondering if I would be able to interview you for my MRP as I would appreciate the opportunity to learn from the work. Ryerson's Research Ethics Board has approved the study and all of the information obtained would be strictly confidential. I will also provide consent forms which include more information about my study so you will be able to have a better understanding of its purpose, how long the interview will take, what the risks are, and who to contact for further inquiry.

\section{Non-Traditional Script:}

To whom it may concern,

I am currently in the Masters of Arts, Early Childhood Studies Degree at Ryerson University. I am pursuing my Major Research Paper (MRP) for my Degree and am emailing you to inquire about possible participation in my study.

I am interested in looking at both non-traditional approaches (such as your work) as well as the more traditional approaches (such as ABA). I am interested in learning how each service functions and through this would like to see how and if disabled children's rights and well-being are being met within the support and programs that children receive.

Having said all of this, I was wondering if I would be able to interview you for my MRP as I would appreciate the opportunity to learn from the work. Ryerson's Research Ethics Board has approved the study and all of the information obtained would be strictly confidential. I will also provide consent forms which include more information about my study so you will be able to have a better understanding of its purpose, how long the interview will take, what the risks are, and who to contact for further inquiry. 


\section{Appendix C \\ Voluntary Consent Forms}

CONSENT FORM

RYERSON

UNIVERSITY

\section{Examining Traditional and Non-Traditional Approaches: Ensuring Disabled Children's Rights and Well-being}

You are being asked to participate in a research study. Before you give your consent to be a volunteer, it is important that you read the following information and ask as many questions as necessary to be sure you understand what you will be asked to do.

\section{Investigators}

This research study is being conducted by Jaclyn Ederman, a graduate student in the Masters of Arts, Early Childhood Studies Department at Ryerson University and is being supervised by Dr. Melanie Panitch, Associate Professor in the School of Disability Studies. This research study is being pursued in partial completion to the degree as a Major Research Paper (MRP). If you have any questions or concerns about the research, please feel free to contact Dr. Panitch at mpanitch@ryerson.ca or at 416-979-5000x.6128.

\section{Purpose and Description of the Study}

This study is being conducted to examine disabled children's rights and well-being by means of exploring service provision. In order to pursue this, two participants will be asked to participate in this study. Participants are eligible if they are service providers who provide support for disabled children through two approaches, one Applied Behavioural Analysis (ABA) and one non-traditional approach.

\section{Description of your Participation}

If you volunteer to participate in this study, you will be asked to:

- Attend one individual in person interview

- Interview will be approximately 1 hour in length

- The location and time will be scheduled at your convenience and to ensure confidentiality I suggest for example, a private room at a public library

- The interview will be audio taped, with your permission

- Questions will be asked about the services you provide such as:

- Who do you provide services for

- What do you do with children

- Participate in a 20-minute follow-up telephone interview to allow for clarification of previously asked questions and completion of missing information, if necessary

\section{Potential Risks and/or Discomforts}

The potential risks of your participation in this study are very low. You will be asked to answer questions about your practices and service provision. This may cause you to question and or reflect upon your practice (psychological risks). If any discomfort is felt, please feel free to say so and or not answer the question by skipping it. In addition, if you still feel uncomfortable, you may discontinue participation temporarily or permanently. Your choice of whether or not to 
participate will note influence your future relations with Ryerson University or the investigators of the study.

\section{Benefits of the Study}

I cannot guarantee that you will receive any benefits from participating in this study. Through participating in this study, potential benefits may be to the fields of early childhood studies, children's rights and perspectives, and disability studies, and the awareness in approaches to supporting disabled children overall.

\section{Confidentiality}

The information that you provide as a participant in this study will be maintained strictly confidential. Raw data (such as written notes and audiotapes) will only be used by myself and for the purpose of analysis. It will be stored on my personal computer that is locked and only accessible by me. In addition, I will use pseudonyms to maintain confidentiality. The raw data will be destroyed following completion of the study in September 2014.

\section{Incentives to Participate}

You will not be paid to participate in this study.

\section{Voluntary Nature of Participation}

Participation in this study is voluntary and you can choose whether to be in this study or not. If you decide to participate at any particular point in the study you may refuse to answer any particular question or stop participation altogether. Your choice of whether or not to participate will not influence your future relations with Ryerson University or myself.

\section{Questions about the Study}

If you have any questions about the research now, please ask. If you have questions later about the research you may contact myself, Jaclyn Ederman (jaclyn.ederman@ryerson.ca) or my supervisor, Dr. Panitch (416-979-5000 x. 6128).

If you have questions regarding your rights as a human subject and participant in this study, you may contact the Ryerson University Research Ethics Board for information.

Research Ethics Board

c/o Office of the Vice President, Research and Innovation

Ryerson University

350 Victoria Street

Toronto, ON, M5B 2K3

416-979-5042 


\section{Signature and Agreement}

Your signature below indicates that you have read the information in this agreement and have had a chance to ask any questions you have about the study: Examining Traditional and NonTraditional Approaches: Ensuring Disabled Children's Rights and Well-being. Your signature also indicates that you agree to be in the study and have been told that you can change your mind and withdraw your consent to participate at any time. You have been given a copy of this agreement.

You have been told that by signing this consent agreement you are not giving up any of your legal rights.

Name of Participant (please print)

In signing the line below, I acknowledge and give my permission to participate in the interview:

Signature of Participant

Signature of Investigator
Date

Date

In signing the line below, I acknowledge and give my permission for the interview to be audiotaped:

Signature of Participant

Signature of Investigator
Date

Date 


\section{Appendix D \\ Interview Protocol}

1. Can you tell me about the work you do?

- What is your title?

- What is your program/service called?

2. Who do you serve?

- Are there restrictions/criterion for individuals being admitted to the program/service? Based on what eligibility? Is there any?

- Why or why not? Who decides this?

- Do you serve children/youth/adults? Specific ages?

- Specific disabilities/abilities?

- Within a particular neighborhood?

3. What program/service do you offer?

- Can you please describe your service?

- Do you provide more than one?

- How do you provide this?

- Group or individually?

- Where is the location?

- Where are they offered? Does the location change? What might this depend on?

- How often do children come to you per week/month/year?

- Do children come for year or years? What does this depend on?

- How long does a session/program last per day (hours)?

- Where do children typically go for support after your program?

- Do you follow up with children and families after they move on?

- How?

4. What are the goals of the program/service?

- What do you expect from the children?

- What do they expect from you?

- How do you reach these goals? Are specific plans used?

- If so, who develops them? Is it done collaboratively with the child and the family, with other professionals?

- Does each child have their own plan? What is this based on?

- How do you measure and evaluate the child's success?

- Do you share this with the family, other professionals?

- Are the children aware of the goals and expectations during service provision?

- Do the children have expectations to follow up or keep up with these goals (i.e. work on $\mathrm{X}$ for next week)?

5. In $X$ in particular (an example of a service they described above), can you please describe...

- What do you do with the child/children?

- How do they participate? What are they involved in?

- How do they respond?

- Can you explain a typical example of a program or session? Are there typical ones? 
- How does a child benefit from this example and program in particular?

6. Do some children not like a program/service that they are participating in?

- Does this happen?

- How often?

- What is this usually about?

- How do children express this?

- How do you respond to this?

- Can you provide me with an example?

7. Who else is involved with your service provision?

- Do you work, collaborate, and or communicate with other professionals? Families? Children?

- If so, how? Can you provide an example?

- If not, would you like to or is it unnecessary for your work?

8. How is your program/service funded?

- Does the government assist with funding for your program/service?

- Does the government assist families with funding?

- How much does your program/service cost?

- What is this based on? Does it change? How is this decided?

- Can families apply for subsidy or grants to receive your programs?

- How do families hear about your program/service?

9. What policies govern your program/service?

- How do you keep services updated to keep up with policy changes?

- How do you evaluate yourself and your program/service to see if they are working/successful?

10. Can you tell me about your background/experience/training?

- Do you have specific training?

- If so what kind? Where did you receive this?

- Is it necessary?

- Do other professionals/individuals that you work with in the field or in your program/service have specific training?

- Do you believe others need a particular background to work within the field?

- In your opinion do you believe education is more important than experience?

- Is there a debate? Do you prefer one over the other? What do you look for in employers/employees/professionals to collaborate or work with and assist with your program and support to children?

- Do you receive ongoing professional development?

- If so what kind? How often? Do you believe it is useful?

- Do you provide professional development for others?

- If so what kind? How often? To whom, families, professionals, schools, etc.?

11. What are some of the challenges that you experience within the field/your work?

- Do you experience any challenges? Can you describe/explain them? What are they about? 
- Funding? Policies?

- Waitlists? Is there a high demand? Competition?

- Children/families? Had to stop services for a child for example? For what reasons?

12. Do you have a vision for your program/service?

- What does it look like?

- What would you like to see five years down the road?

- Regarding your program/service?

- Regarding yourself?

- Regarding the field overall?

- Regarding the children and families you work with? 


\section{References}

Ajodhia-Andrews, A., \& Berman, R. (2009). Exploring school life from the lens of a child who does not use speech to communicate. Qualitative Inquiry, 15(5), 931- 951. doi:10.1177/1077800408322789

American Psychiatric Association. (2013). DSM-5 autism spectrum disorder fact sheet. American Psychiatric Publishing. Retrieved from http://www.dsm5.org/Documents/Autism\%20Spectrum\%20Disorder\%20Fact\%20Sheet.p $\underline{\mathrm{df}}$

Anderson, C. (2010). Presenting and evaluating qualitative research. American Journal of Pharmaceutical Education, 74(8), 141-147. http://dx.doi.org/10.5688/aj7408141

April, K. T, Feldman, D. E., Zunzunegui, M. V., Descarreaux, M., \& Grilli, L. (2009). Complementary and alternative health care use in young children with physical disabilities waiting for rehabilitation services in Canada. Disability \& Rehabilitation, 31(25), 2111-2117. doi:10.3109/09638280902937407

Bennett, B., \& Wynne, K. (2006). Special education transformation: The report of the co-chairs with the recommendations of the working table on special education. Retrieved from http://www.edu.gov.on.ca/eng/document/reports/speced/transformation/transformation.pd $\underline{\mathrm{f}}$

Creswell, J. W. (2014). Research design: Qualitative, quantitative, and mixed methods approaches $\left(4^{\text {th }}\right.$ ed.). Thousand Oaks, CA: Sage Publications Inc.

Currie, R. (2014, July 21). Will our disabled children be accepted? Globe and Mail. Retrieved from http://www.theglobeandmail.com/globe-debate/will-our-children-be$\underline{\text { accepted/article19675556/ }}$ 
Gasalberti, D. (2006). Alternative therapies for children and youth with special health care needs. Journal of Pediatric Health Care, 20(2), 133-136. doi:10.1016/j.pedhc.2005.12.015

Glynne-Owen, R. (2010). Early intervention and autism: The impact of positivism and the call for change. International Journal of Children's Rights, 18(3), 405-416. doi:10.1163/157181810X497431

Goar, C. (2014, July 29). Deaf-blind woman tests Canada's equality guarantee: Goar. Toronto Star. Retrieved from http://www.thestar.com/opinion/commentary/2014/07/29/deafblind_woman_tests_canada s_equality guarantee goar.html

Graham, A., \& Fitzgerald, R. (2011). Supporting children's social and emotional well-being: Does ‘having a say’ matter? Children \& Society, 25(5), 447-457. doi:10.1111/j.10990860.2010.00295.x

Grindle, C. F., Kovshoff, H., Hastings, R. P., \& Remington, B. (2009). Parents experiences of home-based applied behavior analysis programs for young children with autism. Journal of Autism and Developmental Disorders, 39(1), 42-56. doi:10.1007/s10803-008-0597-z

Hayward, D. W., Gale, C. M., \& Eikeseth, S. (2009). Intensive behavioural intervention for young children with autism: A research-based service model. Research in Autism Spectrum Disorders, 3(3), 571-580. doi:10.1016/j.rasd.2008.12.002

Heitzman-Powell, L. S., Buzhardt, J., Rusinko, L. C., \& Miller, T. M. (2014). Formative evaluation of an $\mathrm{ABA}$ outreach training program for parents of children with autism in remote areas. Focus on Autism and Other Developmental Disabilities, 29(1), 23-38. doi:10.1177/1088357613504992 
Iannacci, L., \& Graham, B. (2013). Addressing divides and binaries in early childhood education: Disability, discourse and theory, and practice in a bachelor of education program. In V. Pacini-Ketchabaw \& L. Prochner (Eds.), Re-situating Canadian Early Childhood Education (p. 53-72). New York: Peter Lang.

James, A. (2007). Giving voice to children's voices: Practices and problems, pitfalls and potentials. American Anthropologist, 109(2), 261-272. doi:10.1525/AA.2007.109.2.261

Juneja, M., Mukherjee, S. B., Sharma, S., Jain, R., Das, B., \& Sabu, P. (2012). Evaluation of a parent-based behavioral intervention program for children with autism in a low-resource setting. Journal of Pediatric Neurosciences, 7(1), 16-18. doi:10.4103/1817-1745.97612

Kapp, S. K. (2011). Navajo and autism: The beauty of harmony. Disability \& Society, 26(5), 583- 595. doi:10.1080/09687599.2011.589192

Ladd, R. E. (2005). Rights of the autistic child. The International Journal of Children's Rights, 13(1-2), 87-98. doi:10.1163/1571818054545303

Leeb, R. T., Bitsko, R. H., Merrick, M. T., \& Armour, B. S. (2012). Does childhood disability increase risk for child abuse and neglect? Journal of Mental Health Research in Intellectual Disabilities, 5(1), 4-31. doi:10.1080/19315864.2011.608154

Lenz-Taguchi, H. (2011). Investigating learning, participation and becoming in early childhood practices with a relational materialist approach. Global Studies of Childhood, 1(1), 36-50. doi:http://dx.doi.org/10.2304/gsch.2011.1.1.36

Matthews, S. H. (2007). A window on the 'new' sociology of childhood. Sociology Compass, l(1), 322-334. doi:10.1111/j.1751-9020.2007.00001.x 
Maxwell, C. H., Hano, I. H., Skivington, M. (2007). Qualitative research in rehabilitation counseling. Rehabilitation Counseling Bulletin, 50(2), 99-110. doi:10.1177/00343552070500020801

McPhilemy, C., \& Dillenburger, K. (2013). Parents' experiences of applied behaviour analysis (ABA)-based interventions for children diagnosed with autistic spectrum disorder. British Journal of Special Education, 40(4), 154-161. doi:10.1111/1467-8578.12038

Ministry of Children and Youth Services. (2013). Services for children and youth with special needs in Ontario, and their families: Opportunities for improving their experiences and outcomes. Retrieved from http://www.children.gov.on.ca/htdocs/English/documents/topics/specialneeds/PAreport.p df

Ministry of Children and Youth Services. (2011a). Guidelines, applied behaviour analysis-based services and supports for children and youth with ASD. Retrieved from http://www.children.gov.on.ca/htdocs/English/documents/topics/specialneeds/autism/aba _guidelines-2011.pdf

Ministry of Children and Youth Services. (2011b). Results-based plan briefing book 2010-11. http://www.children.gov.on.ca/htdocs/english/documents/about/Results_2010-2011.pdf

Ministry of Community and Social Services. (2008). About the accessibility for Ontarians with disabilities act, 2005 (AODA). Retrieved from http://www.mcss.gov.on.ca/documents/en/mcss/publications/accessibility/AboutAODA Web20080311EN.pdf

Ministry of Education. (2014). An introduction to special education in Ontario. Retrieved from http://www.edu.gov.on.ca/eng/general/elemsec/speced/ontario.html 
Nieuwenhuys, O. (2013). Theorizing childhood(s): Why we need postcolonial perspectives. Childhood, 20(1), 3-8. doi: 10.1177/0907568212465534

Prothmann, A., Ettrich, C., \& Prothmann, S. (2009). Preference for, and responsiveness to, people, dogs and objects in children with autism. Anthrozoös, 22(2), 161-171. doi: $10.2752 / 175303709 X 434185$

Robb, P. (2014, July 12). The autism story from another point of view. Ottawa Citizen. Retrieved from http://ottawacitizen.com/entertainment/books/the-autism-story-from-another-pointof-view

Sams, M. J., Fortney, E. V., \& Willenbring, S. (2006). Occupational therapy incorporating animals for children with autism: A pilot investigation. The American Journal of Occupational Therapy, 60(3), 268-274. doi:10.5014/ajot.60.3.268

Silva, K., Correia, R., Lima, M., Magahaes, A., \& deSousa, L. (2011). Can dogs prime autistic children for therapy? Evidence from a single case study. Journal of Alternative and Complementary Medicine, 17(7), 655-659. doi:10.1089/acm.2010.0436

Smart, J. F. (2009). The power of models of disability. Journal of Rehabilitation, 75(2), 3-11. Retrieved from http://search.proquest.com/docview/236294941/fulltextPDF?accountid=13631

Stalker, K., \& Connors, C. (2003). Communicating with disabled children. Adoption \& Fostering, 27(1), 26-35. doi:10.1177/030857590302700105

Steege, M. W., Mace, F. C., Perry, L., \& Longenecker, H. (2007). Applied behavior analysis: Beyond discrete trial teaching. Psychology in the Schools, 44(1), 91-99. doi:10.1002/pits.20208 
Tisdall, E. K. M. (2012). The challenge and challenging of childhood studies? Learning from disability studies and research with disabled children. Children \& Society, 26(3), 181191. doi:10.1111/j.1099-0860.2012.00431.x

Unicef. (2014). The state of the world's children 2014 in numbers, every child counts: Revealing disparities, advancing children's rights. Retrieved from http://www.unicef.org/publications/files/SOWC2014_In_Numbers_28_Jan.pdf

United Nations. (2014). Committee on the rights of persons with disabilities: Convention on the rights of persons with disabilities. Retrieved from http://www.ohchr.org/EN/HRBodies/CRPD/Pages/ConventionRightsPersonsWithDisabil ities.aspx

United Nations. (2009). Report of the committee on the rights of persons with disabilities on its first session. Retrieved from http://tbinternet.ohchr.org/_layouts/treatybodyexternal/TBSearch.aspx?Lang=en\&TreatyI $\underline{\mathrm{D}=4 \& \text { DocTypeID }=27}$

United Nations. (1990). Convention on the rights of the child. Retrieved from http://www.ohchr.org/Documents/ProfessionalInterest/crc.pdf

Vandergrift, K., \& Bennett, S. (2012). Children's rights: A framework for health promotion. Healthcare Quarterly, 15,(4) 15-17. doi:10.12927/hcq.2013.22947

Watson, N. (2012). Theorising the lives of disabled children: How can disability theory help? Children \& Society, 26(3), 192-202. doi:10.1111/j.1099-0860.2012.00432.x

Young, R. L. \& Rodi, M. L. (2014). Redefining autism spectrum disorder using DSM-5: The implications of the proposed DSM-5 criteria for autism spectrum disorders. Journal of Autism and Developmental Disorders, 44(4), 758-765. doi:10.1007/s10803-013-1927-3 